\title{
THE ROLE OF STRATEGIC AND OPERATIONAL ABSORPTIVE CAPACITY IN ORGANIZATIONAL AMBIDEXTERITY
}

\begin{tabular}{|c|}
\hline $\begin{array}{c}\text { A Dissertation } \\
\text { Submitted to the } \\
\text { Temple University Graduate Board }\end{array}$ \\
\hline $\begin{array}{l}\text { In Partial Fulfillment } \\
\text { of the Requirements for the Degree } \\
\text { DOCTOR } \\
\text { OF BUSINESS ADMINISTATION }\end{array}$ \\
\hline $\begin{array}{c}\text { by } \\
\text { Ivan Diaz-Molina } \\
\text { Temple University, Fox School of Business } \\
\text { May, } 2019\end{array}$ \\
\hline Examining Committee Members: \\
\hline $\begin{array}{l}\text { Charlotte Ren, Advisory Chair, Strategic Management } \\
\text { Ram Mudambi, Strategic Management } \\
\text { Joan Allatta, Strategic Management } \\
\text { Min-Seok Pang, Management Information Systems }\end{array}$ \\
\hline
\end{tabular}


(C)

Copyright

2019

by

Ivan Diaz - Molina

All Rights Reserved 


\begin{abstract}
In today's dynamic corporate environment where firms struggle to maintain a competitive advantage, ambidextrous firms focusing on both exploration and exploitation are more likely to survive and prosper in the long run. Scholars have identified and examined a number of antecedents of organizational ambidexterity, but extant studies have not fully explored the role of a firm's absorptive capacity in developing its organizational ambidexterity. The relevance of the absorptive capacity concept is paramount since new sources of competitive advantage would very likely come from outside the organizations. In this research, I explore the relationship between a firm's absorptive capacity and organizational ambidexterity by focusing on two levels of absorptive capacity and three dimensions of organizational ambidexterity. Using a survey of 5,600 companies performed by the Government of Chile in 2015, and then a subsample of panel data that includes 760 companies for the 2009-2014 period, I find that both strategic and operational absorptive capacity contribute to the incremental exploitation dimension of organizational ambidexterity. My study contributes to our understanding of the absorptive capacity construct and illuminates how it affects organizational ambidexterity. The study also provides managerial implications as to what kind of external knowledge to procure and how to leverage it based on the firm's ambidexterity goals.
\end{abstract}


To Ivan, Rocio, Luz and Javiera, with all my love. 


\section{ACKNOWLEDGMENTS}

I am deeply grateful to Dr. Charlotte Ren for her insightful comments and clear guidance. I also extend my gratitude to the members of my Examining Committee, Drs. Ram Mudambi, Joan Allatta, and Min-Seok Pang for their advice and comments. Finally, my deepest gratitude to the ESE Business School, for its financial support and my colleagues for their continuous encouragement during this time. 


\section{TABLE OF CONTENTS}

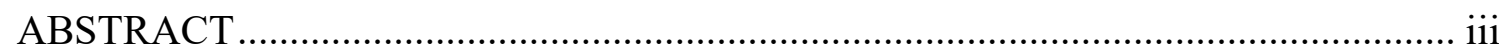

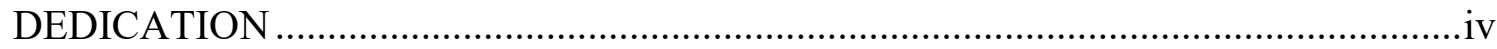

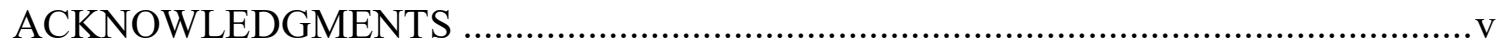

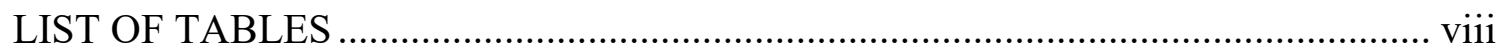

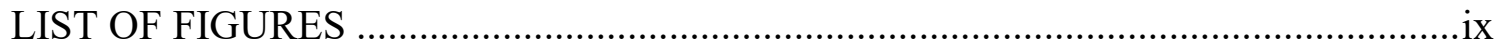

CHAPTER 1

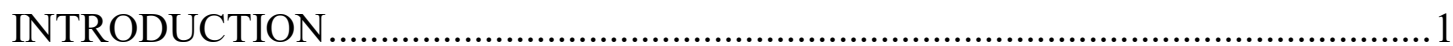

CHAPTER 2

THE ROLE OF STRATEGIC AND OPERATIONAL ABSORPTIVE CAPACITY

IN ORGANIZATIONAL AMBIDEXTERITY …..................................................

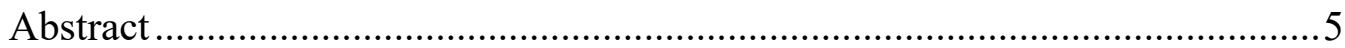

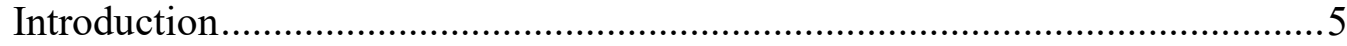

Literature Review and Hypotheses .....................................................

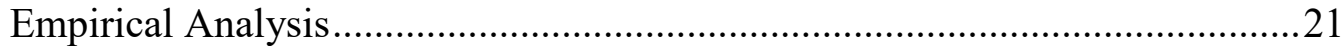

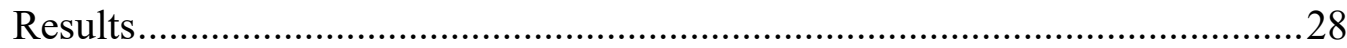

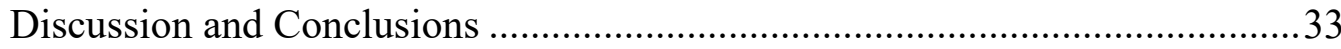

CHAPTER 3

THE ROLE OF STRATEGIC AND OPERATIONAL ABSORPTIVE CAPACITY IN ORGANIZATIONAL AMBIDEXTERITY - A LONGITUDINAL STUDY.......36

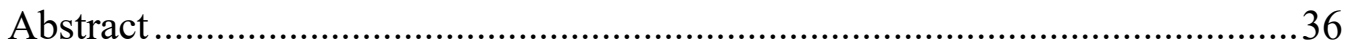




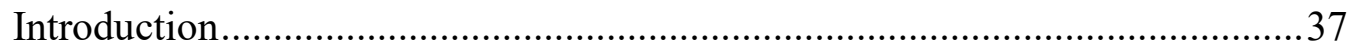

Conceptual Model and Hypotheses ............................................................4 44

Empirical Analysis ........................................................................... 51

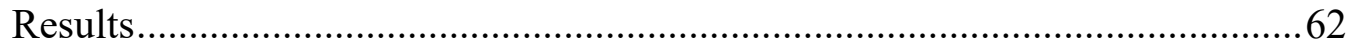

Discussion and Conclusions ................................................................ 78

\section{CHAPTER 4}

CONCLUSIONS

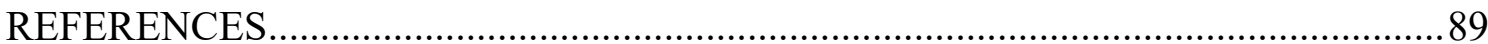




\section{LIST OF TABLES}

Table Page

2.1 Factor Analysis for Two IVs and Three DVs 25

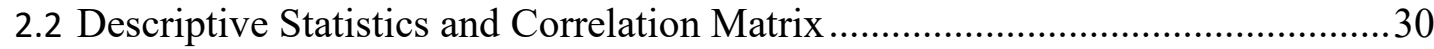

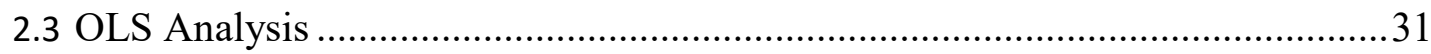

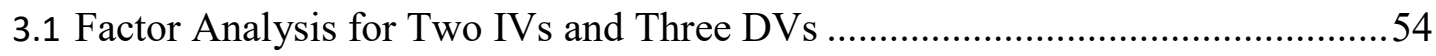

3.2 Explanatory Power of Model with New Operational Absorptive Capacity.........56

3.3 Summary of H1 Analysis using OLS, Fixed, and Random Effects Models........61

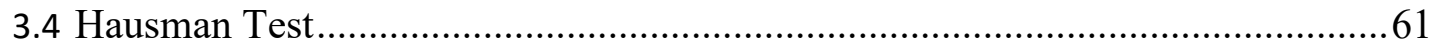

3.5 Descriptive Statistics for H1 DV and IV (control variables omitted) .................63

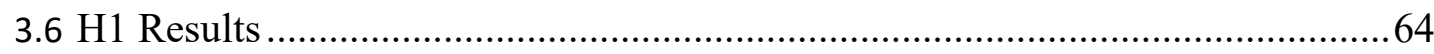

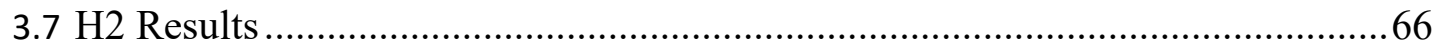

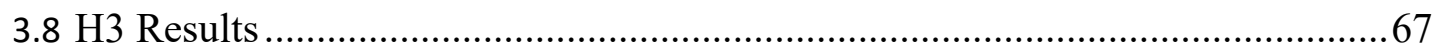

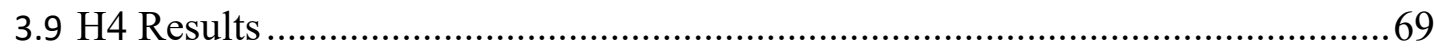

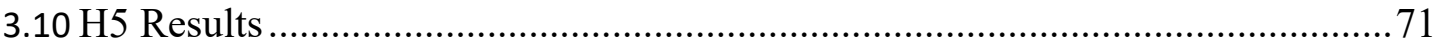

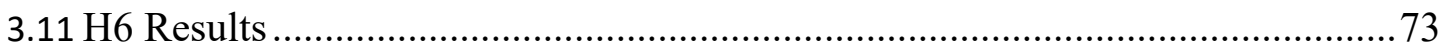

3.12 SACAP and OACAP Interaction for EXPLORE …....................................... 76

3.13 SACAP and OACAP Interaction for IEXPLOITE ....................................... 77 


\section{LIST OF FIGURES}

Figure

Page

2.1 Antecedents of absorptive capacity and its role in organizational ambidexterity 20

3.1 Moderators to the Absorptive Capacity and Ambidexterity relationship ............52

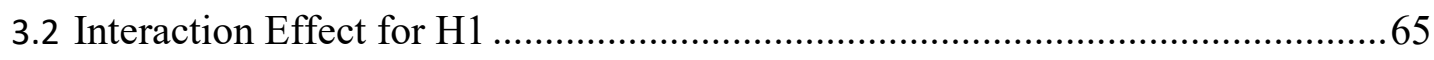

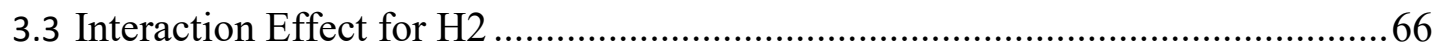

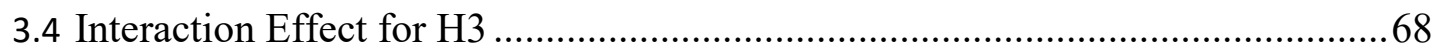

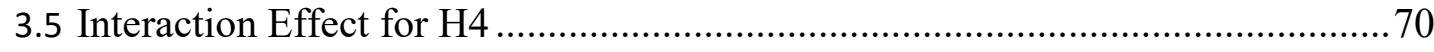

3.6 Chile's Innovation Incentive Legislation, Tax Credits Claims ........................... 72

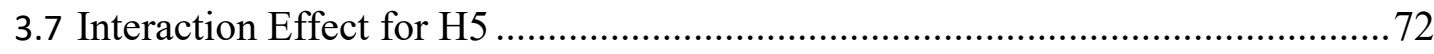

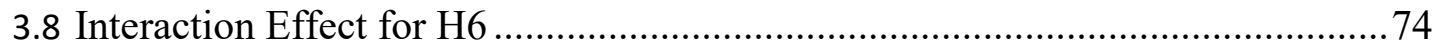

3.9 SACAP and OACAP Interaction for EXPLORE .......................................... 76

3.10 SACAP and OACAP Interaction for IEXPLOITE …....................................... 77 


\section{CHAPTER 1}

\section{INTRODUCTION}

Organizations which enjoy long-term success are becoming a rarity, and the average company life is shortening at an accelerating pace (Goodburn, 2015). There are many reasons for this trend. However, the common denominator is that with companies focusing on short-term goals, it is becoming harder to maintain a competitive advantage in today's dynamic environment. Firms focusing on the tactical use of competitive advantages (i.e., exploiting) while at the same time looking to acquire the next set of competitive advantages (i.e., exploring) are more likely to survive and prosper in the long run than firms focusing on only one or the other. Several examples support this capability, 3M with its teams of scouts, entrepreneurs and implementers transits from exploration to exploitation seamlessly and with significant value creation; another case is Ely Lilly, the pharmaceutical firm, with a research, development and innovation collaboration program where the firm teams up with entrepreneurs and small firms in creating new molecules, products and business cases. The IT sector has also evolved to include ambidexterity, with Cisco's entrepreneurs in residence program, the firm has reached out (absorptive capacity) to include entrepreneurs in the development of new products, processes or business models (ambidexterity). Finally, IBM's Watson open innovation business model, whereby the firm allows third parties to develop innovations using Watson and partnering with the latter if the new product or service is promising.

In academia, a firm's ability to exploit and explore has been studied extensively. Researchers advocate that the two activities should be undertaken sequentially (Duncan, 
1976), cyclically (Boumgarden, Nickerson, \& Zenger, 2012; Mudambi \& Swift, 2011, 2014; Swift, 2016), or simultaneously (O'Reilly \& Tushman, 2013; Ren \& Guo, 2011), the latter is known as organizational ambidexterity.

Studies have identified and explored many antecedents to organizational ambidexterity, but there is still a gap in the literature on the impact of external knowledge on this construct. The relevance of what Cohen and Levinthal (1989, 1990: 129) defined as "absorptive capacity," or the "ability of a firm to recognize, assimilate, and apply new knowledge," is paramount since new competitive advantages will very likely come from this source. The direct relationship between absorptive capacity and organizational ambidexterity remains mostly unexplored, except for studies by Datta (2012), and Yan, Yu, and Dong (2016). Additionally, studies of absorptive capacity have been conducted by researchers independently in the innovation and operations fields, without exploring the impact of the simultaneous effect in both fields.

In Chapter 2, I borrow from organizational learning and operational theories to introduce a multileveled absorptive capacity construct. This construct includes a strategic element defined as the ability of top management to recognize and interpret the opportunity of disruptive innovations, based on Cohen and Levinthal (1990) and Yan et al. (2016), and an operational element defined as "the ability of a firm's operational unit to acquire, assimilate, transform and exploit knowledge from the operations environment" (Patel, Terjesen, \& Li, 2012, p. 202). I theorize that strategic and operational absorptive capacities independently exert a positive influence in the exploration and repetitive exploitation dimensions of ambidexterity. Further, strategic and operational absorptive capacities concurrently positively influence the ability of the 
firm to perform incremental innovation, defined by Piao and Zajac (2016) as incremental exploitation.

Innovation and ambidexterity are considered critical dynamic capabilities because they represent a driver for change within the organization (O'Reilly \& Tushman, 2008; Wang \& Ahmed, 2007). The model I explore in Chapter 2 on how strategic and operational absorptive capacity affect organizational ambidexterity shows a significant positive relationship between both constructs, but it remains a static representation of a more complex and dynamic problem. Studies conducted on panel data from New Zealand and the UK demonstrate that the impact of absorptive capacity on a firm's ability to explore changes over time (Harris \& Moffat, 2011; Harris \& Moffat, 2013; Harris \& Le, 2018). Also, a large amount of literature has touched upon the variation of ambidexterity over time and its impact on firm performance and innovation capacity (Ahuja \& Morris Lampert, 2001; Benner \& Tushman, 2003; Phelps, 2010; Uotila, Maula, Keil, \& Zahra, 2009).

Comprehensive surveys conducted by the World Economic Forum (i.e. the Global Competitiveness Index) and INSEAD with Cornell University (i.e. the Global Innovation Index) conclude that, government-sponsored private investments in R\&D and joint ventures or strategic alliance deals are among the more influential factors in the innovation and competitive capabilities of companies (Dutta, Lanvin, \& WunschVincent, 2016; Schwab \& Sala-i-Martin, 2018). Furthermore, there is a discrepancy in the literature regarding the use of absorptive capacity and its effect on ambidexterity by companies in the manufacturing versus service sectors (Álvarez, Bravo-Ortega, \& Zahler, 2015; Arbussa \& Coenders, 2007; Mina, Bascavusoglu-Moreau, \& Hughes, 2014). 
In Chapter 3, I explore the relationship between both constructs over time and focus on the moderating effects of industry sector (i.e., service vs. manufacturing), collaboration activities, and innovation-promoting legislation. I begin with a literature review describing all longitudinal studies about absorptive capacity and ambidexterity, the relevance of absorptive capacity on national-level innovation efforts, and the variation in relevant variables over the period under study in Chile. I then describe the panel data set and my statistical approach, followed by a results section. I conclude by discussing the theoretical and managerial contributions as well as directions for future research.

Chapter 4 includes the overall conclusions of this dissertation along with proposed avenues of future research. 


\title{
CHAPTER 2
}

\section{THE ROLE OF STRATEGIC AND OPERATIONAL ABSORPTIVE CAPACITY IN ORGANIZATIONAL AMBIDEXTERITY}

\begin{abstract}
Scholars have identified and examined a number of antecedents of organizational ambidexterity, but extant studies have not yet fully explored the role of a firm's absorptive capacity in developing its organizational ambidexterity. Absorptive capacity is supremely relevant to any discussion of firm organization ambidexterity since new sources of competitive advantage likely come from outside the organizations. In this study, I examine this relationship by focusing on two levels of absorptive capacity and three dimensions of organizational ambidexterity. Using a survey of 5,600 companies performed by the Government of Chile in 2015, I find that both strategic and operational absorptive capacity contribute to the incremental exploitation dimension of organizational ambidexterity. My study contributes to our understanding of the absorptive capacity construct and illuminates how it affects organizational ambidexterity. The study also provides managerial implications as to what kind of external knowledge to procure and how to leverage it based on the firm's ambidexterity goals.
\end{abstract}

\section{Introduction}

Long-term successful organizations are becoming a rarity, while average company life is shortening at an increasing pace (Goodburn, 2015). There are many reasons for this trend, but the common denominator is that it is becoming harder to maintain competitive advantages in today's dynamic environment, with companies 
focusing on short-term goals. Firms focusing on the tactical use of competitive advantages (i.e., exploiting) and, at the same time, looking to acquire the next set of competitive advantages (i.e., exploring) are more likely to survive in the long run. In academia, the ability of a firm to exploit and explore has already been studied extensively. Researchers claim that the two activities should be undertaken sequentially (Duncan, 1976), cyclically (Boumgarden et al., 2012; Mudambi \& Swift, 2011, 2014; Swift, 2016), and simultaneously, the latter known as organizational ambidexterity (O'Reilly \& Tushman, 2013).

Studies have identified and explored many antecedents to the construct, but there is still a gap in the literature on the impact of external knowledge on organizational ambidexterity. The relevance of what Cohen and Levinthal (1989, 1990) defined as "absorptive capacity," or the ability of a firm to recognize, assimilate, and apply new knowledge, is paramount since new competitive advantages will very likely come from this source. The direct relationship between absorptive capacity and ambidexterity, the primary focus of this study, remains mostly unexplored except for the studies by Datta (2012), and Yan et al. (2016). Additionally, studies of absorptive capacity have been conducted by researchers in the innovation and operations fields independently without exploring the impact of their simultaneous effect.

In the present study, borrowing from organizational learning and operational theories, a multileveled absorptive capacity construct is introduced. It includes a strategic element defined as the ability of top management to recognize and interpret the opportunity of disruptive innovations, based on Cohen and Levinthal (1990), Yan et al. (2016), and an operational element defined as "the ability of a firm's operational 
unit to acquire, assimilate, transform, and exploit knowledge from the operations environment" (Patel et al., 2012, p. 202). It is theorized that strategic and operational absorptive capacity independently exert a positive influence in the exploration and repetitive exploitation dimensions of ambidexterity respectively. Concurrently, strategic and operational absorptive capacity also influence positively the ability of the firm to perform incremental innovation, defined by Piao and Zajac as incremental exploitation (2016).

The rest of this chapter is organized as follows: I start with a literature review and develop hypotheses on the relationships between absorptive capacity and organizational ambidexterity. Next, I describe the data, methods, and results of the data analysis. I then discuss the study's contributions to theory and practice, its limitations, and future research areas.

\section{Literature Review and Hypotheses}

\section{Organizational Ambidexterity: Exploration and Exploitation}

The concepts of exploration and exploitation adopted from the field of adaptive processes were first formulated by March (1991). He recognized that exploration and exploitation are both essential for organizations, and must compete for the firm's limited resources available. Exploration is here defined as the pursuit of new knowledge, whereas exploitation was the use and development of things already known. From a learning perspective, these definitions are focused on the type and amount of learning, and on whether learning exploitation followed the same trajectory as old knowledge, while learning exploration followed a different path (Gupta, Smith, \& Shalley, 2006). In this context, exploitation's advantage stems from its proximity to 
the action, clearer ties with its consequences, and therefore less uncertainty. Exploitation seems to have an advantage in this competition because of its proximity to the action, clearer ties with its consequences, and therefore less uncertainty. In contrast, March found that exploration involved more uncertainty, longer terms, and less clarity in its implications. However, March also noted that a lack of equilibrium between exploitation and exploration, with adaptive processes more inclined to exploitation, could become self-destructive; thus, an organization should reach such equilibrium using the process of adaptation.

Different scholars have proposed different tactics aimed at resolving the organizational tension between exploratory and exploitative activities. Some authors suggest externalizing exploitative or exploratory activity by establishing alliances or by outsourcing (Holmqvist, 2004; Rothaermel \& Deeds, 2004). Other authors suggest that firms should cycle between states of exploitation and exploration, defined as a punctuated equilibrium model (Mudambi \& Swift, 2011, 2014; Swift, 2016). Another view is that successful organizations are efficient in their day-to-day activities and in satisfying their actual business demands while at the same time preparing for future challenges and adapting to changing environments (Raisch \& Birkinshaw, 2008; Ren \& Guo, 2011; Tushman \& O'Reilly, 1996). This last view is often referred to as organizational ambidexterity - the ability to "ambidextrously" balance the needs of both exploitation and exploration at the same time.

Organizations that pursue exploitation and exploration, whether simultaneously or sequentially, are more likely to achieve superior performance than organizations prioritizing one over the other (Raisch \& Birkinshaw, 2008). For example, when firms concentrate only on the exploitation of existing competencies, 
they fall into organizational inertia (Anand, Mulotte, \& Ren, 2016). This inertia prevents them from adapting to changing conditions, ultimately leading them to mediocre performance (i.e., the "success trap") in the long run (Levinthal \& March, 1993; Raisch \& Birkinshaw, 2008; Smith \& Tushman, 2005; Tushman \& O'Reilly, 1996). In contrast, if a firm leans too much on exploration, it runs the risk of having too many underdeveloped innovative ideas that fail to generate value (Junni, Sarala, Taras, \& Tarba, 2013).

The prospect of potential success if the tension is balanced has caught the attention of a vast number of researchers from various perspectives. Contributions from organizational learning, strategic management, innovation, organizational design, and adaptation have enriched the discussion on ambidexterity, but have also brought with them a lack of clarity as to the central meaning of organizational ambidexterity (Birkinshaw \& Gupta, 2013). Although, as Birkinshaw and Gupta proposed, "the study of ambidexterity is the study of firms, or indeed organizations more generally" (p. 290), that generalization could deprive the construct of its potential to contribute to the understanding of an actual and complex challenge for businesses. In a meta-analysis of organizational ambidexterity and performance, Junni and colleagues (2013) concluded that "combined" exploration and exploitation, or the independent, orthogonal combination of high levels of exploration and exploitation pursued concurrently within a firm, explain the ambidexterity phenomenon better than "balanced" exploration and exploitation, or equilibrium between both elements of ambidexterity.

Following Junni and colleagues' argument, Piao and Zajac (2016) recognize that the relationship between exploration and exploitation is not a zero-sum game and 
that components of exploitation could impel exploration. The authors introduce the concept of "incremental exploitation," defined as "the creation of new designs for existing products," and "repetitive exploitation" defined as "the repetition of existing designs for existing products" that could potentially impede exploration (p. 1432). Piao and Zajac maintained the well-accepted definition of exploration as "the development of new products aimed at entering new product-market domains" ( $p$. 1432). In this study, I adopt the "combined" view of ambidexterity proposed by Junni et al. and its expansion introduced by Piao and Zajac. Services and processes are also included in the definition.

\section{Absorptive Capacity at the Strategic and Operational Level of the Organization}

The fast pace of change inherent in technology-enabled business models, products, and services requires firms to expand into new resources and capabilities. Rather than developing them internally, companies often look to acquire them from outside. Therefore, the ability to seek and acquire critical resources and capabilities from outside the organization-otherwise known as "absorptive capacity"-has become an essential capability for technologically-minded firms.

The term "absorptive capacity" was introduced by Kedia and Bhagat (1988) in the context of technology transfer between nations, but Cohen and Levinthal's work $(1989,1990)$ is considered the origin of the absorptive capacity construct. Based on the stock of collected knowledge from R\&D activities, Cohen and Levinthal (1990) define absorptive capacity as, "an ability to recognize the value of new information, assimilate it, and apply it to commercial ends" (p. 129). Researchers have since extended the concept from R\&D to other areas. Zahra and George (2002) expand and 
modify the concept by adding the ability to "acquire" new knowledge and dropping the ability to "recognize the value" of knowledge as suggested by Cohen and Levinthal (1990: 129). The first two resulting capabilities, acquisition, and assimilation are grouped and labeled "potential absorptive capacity." Zahra and George (2002: 186) add the ability to transform the assimilated knowledge, grouping transformation and exploitation, under the label "realized absorptive capacity." They also establish that the higher the exposure to diversified and complementary external knowledge, the greater the ability to develop potential absorptive capacity.

Todorova and Durisin's (2007) proposed construct dismiss the categorization by Zahra and George in potential and realized absorptive capacity as unnecessary. However, they retain the addition of acquisition and transformation as key capabilities of the construct and incorporate the dynamic dimension in their model. They also include the ability to "recognize value" originally proposed by Cohen and Levinthal (1990), and suggest that "assimilation" and "transformation" are events that occur in parallel, not sequentially, and that there is an association between them.

Since its inception, absorptive capacity has been associated with new knowledge coming from R\&D, either internal (Cohen \& Levinthal, 1990; Grant, 1996) or external (Lin, Zeng, Liu, \& Li, 2016) and with an almost exclusive emphasis on radical or incremental innovation. From an organizational learning perspective, absorptive capacity is related to strategic learning when dealing with disruptive innovation and with business learning at the operational level (Yan et al., 2016). As the construct became more mature, its application widened, and it was applied to areas such us marketing, finance (Huizingh, 2011), and operations (Fayard, Lee, Leitch, \& Kettinger, 2012; Malhotra, Gosain, \& Sawy, 2005; Patel et al., 2012; Tu, 
Vonderembse, Ragu-Nathan, \& Sharkey, 2006). From the latter, Patel et al. (2012) define operational absorptive capacity as "the ability of a firm's operational unit to acquire, assimilate, transform, and exploit knowledge from the operations environment" (p. 202). Thus, utilizing organizational learning and operational perspective, the construct expanded beyond its innovation focus on efficiency and productivity. This development is natural since the contribution of external knowledge is not restricted just to innovation from $R \& D$ but to all functional areas of the firm.

The expansion of absorptive capacity beyond R\&D and innovation to include other operational areas of the organization, and its impact on the exploratory and exploitative abilities of the firm, is the focus of this study. Addressed toward the ambiguity in the literature, the following research question is posed: How do strategic and operational absorptive capacity affect organizational ambidexterity?

\section{Strategic Absorptive Capacity, Exploration, and Incremental Exploitation}

The relationship between absorptive capacity and exploration has been identified in the study of R\&D and innovation in understanding different issues at the firm level. Some examples include studies of external R\&D sources by Lin et al. (2016), "knowledge spillover" as a criterion for locating R\&D facilities by Feinberg and Gupta (2004), and by Ritala \& Hurmmelina-Laukkanen (2013) in the context of coopetition. While studying the flow of knowledge between units of a firm and its impact on radical innovation, van Wijk, Jansen, Van Den Bosch, and Volberda (2012) find that excessive investment in in-depth knowledge beyond a moderate level limits absorptive capacity and subsequently impedes the firm's exploratory capability. 
Starting from recognizing the type of knowledge that exists in an organization (i.e., breadth and depth), Zhou and Li (2012) conclude that companies with a breadth of knowledge across many disciplines and fields find it convenient to concentrate on the dissemination of such knowledge internally to achieve radical innovation. In the case of companies with knowledge depth only in particular fields, the conclusion is to reach out for new knowledge in order to achieve radical innovation.

Inherent to open innovation is the notion of reaching outside the organization for new knowledge. Many studies have recognized absorptive capacity as an open innovation key capability, going as far as stating that absorptive capacity is a precondition to the implementation of open innovation (Spithoven, Clarysse, \& Knockaert, 2010).

The building mechanisms of absorptive capacity have been explained successfully by the organizational learning perspective at different hierarchical levels within the firm (Kim, 1998). Using Hyundai Motor Company as a case study, Kim identifies the company's shift in learning orientation from imitation to innovation and the emphasis on absorptive capacity for the transition. Yan et al. (2016) expand upon this notion by introducing the strategic-business learning typology, which acknowledges different learning outcomes due to efforts at different levels. At the firm-level, strategic learning "leads to a significant impact on the whole organization and causes long-term revolutionary changes, such as new basic assumptions" (p. 653). The authors related strategic learning directly to the explorative capability of organizational ambidexterity and they recognize the beneficial effect of exploration due to the ability of top management to recognize and interpret the opportunity of disruptive innovations. Analyzing the history of Huawei in a longitudinal case study, 
the authors show how the company migrated its strategic learning focus towards external sources including external $\mathrm{R} \& \mathrm{D}$, outside consultants, market reports, strategic alliances, and inter-firm partnerships. This long-term change, characteristic of strategic learning and its external sources involve a high level of commitment by the organization and an expensive and difficult to reverse proposition (Ghemawat, 2002). This strategic learning typology and its external sources is defined, for purposes of this research as "strategic absorptive capacity."

Despite the many research streams identifying a relationship between absorptive capacity and exploration at the firm level, the majority of the studies that have explored this relationship have done so indirectly or through restrictive case studies (Yan et al., 2016). Some studies were conducted under the assumption that absorptive capacity was a moderator of ambidexterity (Narasimhan \& Narayanan, 2013), or an antecedent, simultaneous with ambidexterity, to innovative performance (Lucena \& Roper, 2016); others assumed a partial impact of the absorptive capacity construct (i.e., realized vs. potential) on ambidexterity (Datta, 2012).

To advance the knowledge of the association between strategic absorptive capacity and the exploratory ability of firms, the following hypothesis is proposed:

H1. Strategic absorptive capacity increases the exploratory component of organizational ambidexterity.

In the context of innovation research, several authors have identified that external knowledge is used by organizations as input for their radical and incremental innovation but using different mechanisms (Ritala \& Hurmelinna-Laukkanen, 2013; van Wijk et al., 2012). In the case of incremental innovation, external new knowledge is based on prior knowledge acquired by the company as postulated by Cohen and 
Levinthal (1990) and Lichtenthaler (2009). According to Lichtenthaler, existing knowledge can be put into one of two categories: technological knowledge and market knowledge. Borrowing from Cohen and Levinthal (1990), the author defines "technological knowledge" as knowledge that the firm explores, transforms, and exploits in its absorptive capacity processes, whereas "market knowledge" refers to application and commercialization opportunities for technological knowledge, for example, identifying new applications of technology in new markets. Likewise, Lichtenthaler links exploitative learning with the matching of knowledge and markets (Lichtenthaler, 2009: 823).

An excellent example of Lichtenthaler's postulate is 3M's external knowledge absorption mechanism. Through its $\mathrm{R} \& \mathrm{D}$ and radical innovation initiatives, 3M developed new imaging technology for its medical unit (i.e., exploration) (3M, 2003). Furthermore, the company kept gathering external strategic knowledge, mainly from other industries with similar needs. This knowledge was used to enhance the product or to find other uses for it. In this case, the company applied the technology successfully to mining and construction industries, to locate and identify subsurface formations or buried infrastructure. One could argue that this was a joint effort to gather strategic and operational knowledge from outside the organization to find a different use for the technology, or what could be defined as incremental innovation. Chance did not play any part in this finding since the company has an established process to work permanently on incremental innovation based on their new strategic and operational knowledge. $3 \mathrm{M}$ has defined roles to facilitate this task, breaking up their staff into "scouts," people searching for new opportunities, knowledge, and needs outside the organization (i.e., strategic absorptive capacity); "entrepreneurs," 
individuals focused on converting the opportunities identified into new products, services or processes; and "implementers," employees in charge of taking these new products to market.

At $3 \mathrm{M}$, scouts and entrepreneurs represent the interaction between strategic absorptive capacity and incremental exploitation, viewed as finding new uses for already developed products. This phenomenon is not exclusive to $3 \mathrm{M}$; many other companies have implemented a version of this mechanism, but academia has lagged in studying this phenomenon in detail. Therefore, I engage with this interaction by proposing the following hypothesis:

H2. Strategic absorptive capacity increases the incremental exploitative component of organizational ambidexterity.

\section{Operational Absorptive Capacity, Incremental Exploitation, and Repetitive}

\section{Exploitation}

From an operational viewpoint, Patel et al. (2002) defined operational absorptive capacity as “the ability of a firm's operational units to acquire, assimilate, transform, and exploit knowledge from the operations environment" (p. 202). The authors argue that operational absorptive capacity allows firms to rapidly analyze and act on changes to the operational environment, like changes in demand, to quickly increase the range and mobility of machines, labor, and material. Operational absorptive capacity also allows firms to respond to changes in the competitive landscape by changing the product mix. Finally, the authors state that operational absorptive capacity could influence the company's ability to achieve a competitive advantage through manufacturing flexibility. 
Similarly, Huizingh (2011) recognizes that external knowledge could come from suppliers, customers, competitors, research institutions, and organizations in different industries. The initiatives to collect external knowledge could take the form of a collaborative effort that may last for a significant period and are likely to be repeated. The author cites collaboration between supplier and customer in exploring applications to new technology, or a customer inviting the supplier to participate in a project to reduce waste. Huizingh stresses that these efforts should go beyond R\&D and include other areas of the organization such as marketing, production, logistics, and even finance.

By rapidly responding to environmental or market changes, technological innovation or collaborating with other stakeholders, operational absorptive capacity helps a firm innovate on processes and product mix, and adapt to technological changes to maintain its competitive advantage. For purposes of this research, Patel et al.'s (2012) definition will be complemented with Hiuzingh's (2001) more comprehensive view which includes other areas of the organization impacted by potential incremental innovation. Therefore, operational absorptive capacity is defined as "the ability of a firm's operational units to acquire, assimilate, transform, and exploit knowledge" (Patel et al. 2012, p. 202) from suppliers, customers, competitors, research institutions, organizations in different industries, and the operations environment in general.

As presented by Patel et al. (2012) and in the 3M case, incremental innovations require the intervention of operational knowledge, to adapt existing products or services to other uses or clients, innovate on processes, modify the product mix, and react to technological changes. I thus propose the following hypothesis: 
H3. Operational absorptive capacity increases the incremental exploitative component of the ambidexterity capability of an organization.

Cohen \& Levinthal (1990) intended for the absorptive capacity construct to be applied to the entire organization, despite focusing its applicability on R\&D and innovation. The authors explicitly identified the construct's use to reorganize or automate particular manufacturing processes. Firms also invest in absorptive capacity directly, as when "they send personnel for advanced technical training” (p. 129).

Tu et al. (2006) reported the positive effect of absorptive capacity on timebased manufacturing practices and its positive impact on operational performance. Focusing on supply chain efficiency, Malhotra et al. (2005) identify five configurations of partnerships, with the collaborative type creating the highest level of absorptive capacity and operational efficiency. With an emphasis on supply chain costs, Fayard et al. (2012) conclude that absorptive capacity was vital in the ability to manage external costs originated by collaboration with suppliers.

From an operational risk perspective, Hora and Klassen (2013) recognize that firms' need to acquire external knowledge regarding problems that occur in others' processes to improve their operations and avoid similar losses. Proper mitigation of operational and supply chain risks could have important implications for customer safety and operational competitiveness and could even affect the industry as a whole (e.g., an oil spill, food contamination, or recall of defective products). Operational absorptive capacity plays a relevant role in acquiring the necessary external knowledge in the form of "lessons learned" in order to improve the risk profile of a firm's operation. Setia and Patel (2013), in a study of the interaction between information technology (IT) and operational absorptive capacity, conclude that since 
ITs are the backbone of operational activities, IT-enabled operational absorptive capacities may help build operational knowledge management capabilities and improve operations.

These and other studies have validated the effect of operational absorptive capacity on organizational efficiency and productivity, but they have been done in isolation as if absorptive capacity only resided in the operational area of the firm. As discussed before, Yan et al. (2016) introduce the strategic-business learning typology to evaluate different learning outcomes. The authors identify performance reviews, training, best practices, and working and reward systems as closely associated with business learning. These business learnings are required to achieve incremental improvements, but they do not come exclusively from within the organization, as prior knowledge does. Instead, this information typically comes from outside sources such as industry benchmarks and strategic alliances. This description of business learning is coincidental to Patel et al.'s (2012) definition of operational absorptive capacity. For purposes of this study, both constructs will be considered the same and defined after Patel et al.'s operational absorptive capacity.

To investigate the contribution of operational absorptive capacity to the operational efficiency of the firm (i.e., repetitive exploitation), the following hypothesis is presented:

H4. Operational absorptive capacity increases the repetitive exploitative component of organizational ambidexterity.

Figure 2.1 provides an overview of the proposed model with constructs and hypotheses. 


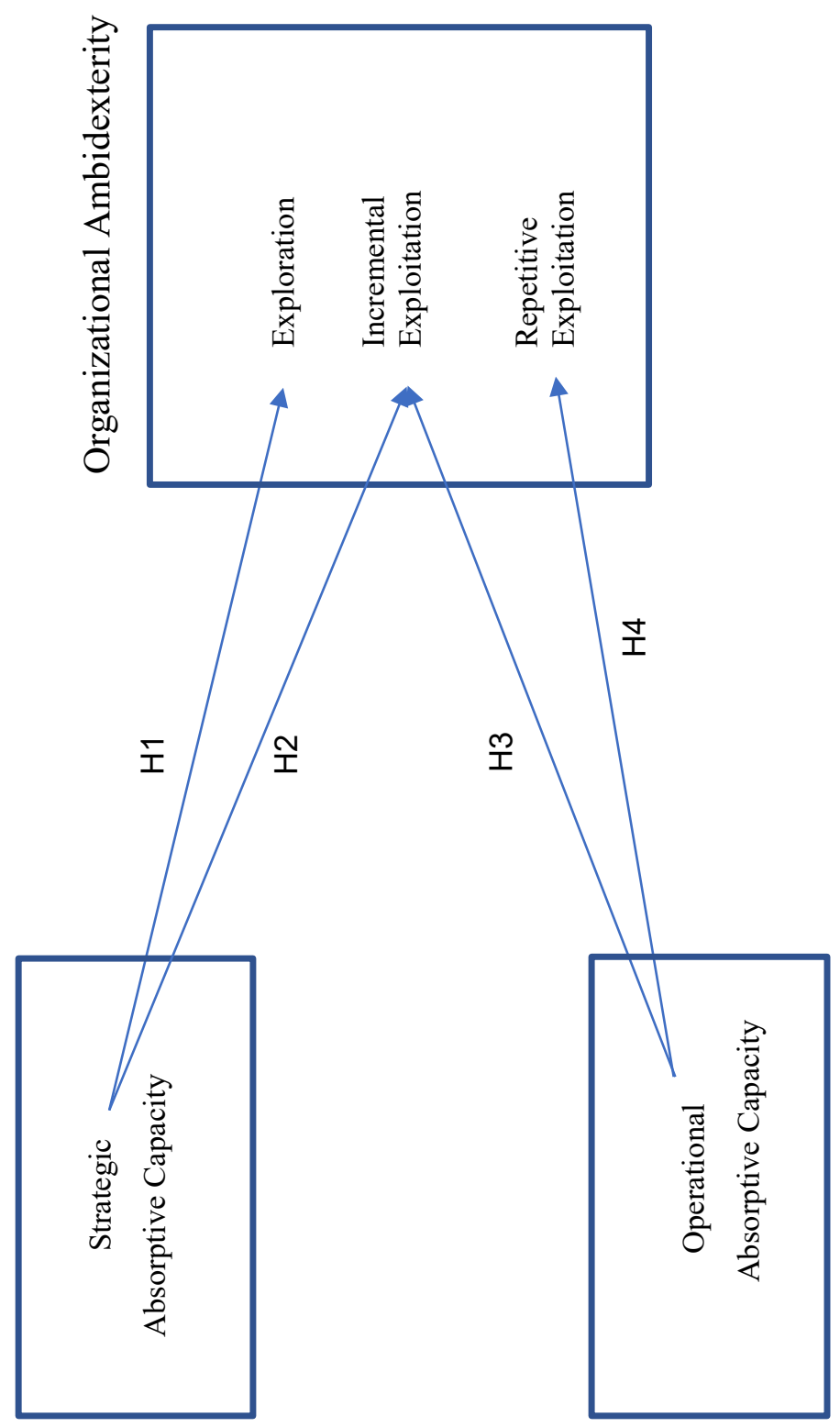

Figure 2.1 Antecedents of absorptive capacity and its role in organizational ambidexterity 


\section{Empirical Analysis}

\section{Data Sample and Data Sources}

The proposed theory assumes that organizations use their absorptive capacity at two distinct levels: the strategic, to draw knowledge and technology from outside the firm and apply it to exploratory actions; and the operational, to incorporate knowledge and technology in order to improve existing products and services (i.e., incremental exploitation) and augment efficiency in existing operations (i.e., repetitive exploitation). These propositions are novel and have not been investigated before. Further, although the constructs have been subjected to previous research, their interaction and boundaries are still not well defined.

Given this context, and the nature of the research questions, I conducted an exploratory quantitative study based on secondary data available from the Chilean National Innovation Survey 2015 of the National Institute of Statistics (Instituto Nacional de Estadistica, 2015). This survey, performed at the firm level, follows the OECD (Organisation for Economic Co-operation and Development) guidelines included in the Oslo Manual (1997). Chile has been conducting this survey for nine consecutive years since its National Innovation Strategy was introduced in 2006. The survey, including data from 2013 and 2014, was done in Chile's 15 regions or states and is classified by their economic activity using the International Standard Industrial Classification (United Nations, 2004).

According to this dataset, small companies are defined as those with sales at or less than $\$ 1.0 \mathrm{~mm}$ per annum; medium-sized companies are those with sales at more than $\$ 1.0 \mathrm{~mm}$, but less than $\$ 4.0 \mathrm{~mm}$, and large companies are defined as those selling 
more than $\$ 4.0 \mathrm{~mm}$. Companies with sales less than $\$ 0.1 \mathrm{~mm}$ are excluded from the study. The total number of companies sampled was 163,418 , with an effective sample size of 5,620 companies, comprised of 2,240 small companies, 1,218 mid-size companies, and 2,162 large ones.

The database is open source, but the confidentiality of the companies is protected by assigning a unique code to each participant, and not disclosing any information that could identify them. The average age of responding firms is 20 years with a standard deviation of 11.22 years. The average size measured as annual sales is $\$ 106 \mathrm{~mm}$ with a standard deviation of $\$ 7.6 \mathrm{~mm}$. In the case of average size measured in number of employees, the average is 184 with a standard deviation of 936 workers. The fact that the standard deviation is so significantly large is due to ten companies having a large number of employees (more than 10,000 employees) in the data set.

\section{Independent Variables}

Strategic absorptive capacity was derived from a factor analysis conducted on a set of questions from the survey addressing the external sources firms reach out to for purposes of their innovation activities (Table 2.1). Since the questions are part of an innovation survey and do not identify the type of activity that the external sources effect, it is assumed that all sources selected by the survey participants refer exclusively to innovation and not operations within the firm. Therefore, all external sources included in the survey are considered proxies of the strategic absorptive capacity: they are classified as market (i.e., suppliers, customers, competitors, and consultants), institutional sources (i.e., universities and research facilities), and others (i.e., conferences, publications, professional associations, and the internet). Answers 
to these ten questions were dichotomous (YES/NO). Thus a polychoric procedure was conducted before the factor analysis. Additionally, the results were rotated for a better fit, and the factors with an eigenvalue higher than 1.0 were retained. Table 2.1 summarizes the resultant loadings for the relevant factor. Strategic absorptive capacity is represented by one underlying factor encompassing $90 \%$ of total variance.

Operational absorptive capacity is defined as the firm's ability to reach outside its boundaries for operational knowledge (i.e., engineering, operational, and information systems). Since an innovation survey is the source of the data utilized, no direct question is related to this type of knowledge. Following Setia and Patel (2013), a proxy is used by assuming that the firm has established engineering and information systems departments and that these departments would reach out for the state-of-theart practices in each area in order to improve operations. Again, three questions with dichotomous answers are used in the questionnaire to cover this area. The same procedure as the one used for strategic absorptive capacity is used to determine the relevant factors. One factor recorded an eigenvalue higher than 1.0, covering $121 \%$ of the total variance. All other remaining factors were negative.

\section{Dependent Variables}

The exploratory function of ambidexterity (EXPLORE) is covered by identifying whether the firm launched new products or services during 2014. According to the Chilean National Innovation Survey 2015, product innovation is the introduction to the market of a new good or service, or a significantly improved good or service, regarding its characteristics or its use. Factor analysis is conducted on these two dichotomous variables (i.e., new or improved goods or services). The same 
procedure for strategic absorptive capacity and operational absorptive capacity is used to determine the relevant underlying factors. One factor proved significant (i.e., eigenvalue larger than 1.0) describing $113 \%$ of the variability, defined as exploration.

Following Piao and Zajac (2016), exploitation is divided into two functions: incremental exploitation, representing incremental innovation or a new design for existing products or processes that I assume is influenced positively by both strategic and operational absorptive capacity; and repetitive exploitation, which is the repetition of existing designs of existing products. Incremental exploitation (IEXPLOITE) is addressed in the survey by four questions regarding improved marketing practices ranging from new packaging to new pricing mechanisms. Factor analysis is conducted on these four dichotomous variables using the same methodology as before. One factor is found to be representative (i.e., eigenvalue greater than 1.0) explaining 104\% of the variability and is defined as incremental exploitation.

Finally, repetitive exploitation (REXPLOITE) is represented by six questions covering incremental improvements in manufacturing, logistics and operational support methods as well as the inclusion of decision making, external relations, and process design practices. Factor analysis is conducted on these six dichotomous variables using the same methodology as before. One factor is found to be representative (i.e., eigenvalue larger than 1.0) explaining $96 \%$ of the variability, defined as repetitive exploitation. Table 2.1 presents the factor analysis results of the dependent and independent variables. 
Table 2.1 Factor Analysis for Two IVs and Three DVs

\begin{tabular}{|c|c|c|c|c|c|c|c|c|c|c|}
\hline \multirow[b]{3}{*}{ Survey Item } & \multirow{2}{*}{\multicolumn{2}{|c|}{$\begin{array}{c}\text { Strategic } \\
\text { Absorptive } \\
\text { Capacity } \\
\text { Loading }\end{array}$}} & \multicolumn{2}{|c|}{$\begin{array}{c}\text { Operational } \\
\text { Absorptive } \\
\text { Capacity }\end{array}$} & \multicolumn{2}{|c|}{ Exploration } & \multicolumn{2}{|c|}{$\begin{array}{l}\text { Incremental } \\
\text { Exploitation }\end{array}$} & \multicolumn{2}{|c|}{$\begin{array}{c}\text { Repetitive } \\
\text { Exploitation }\end{array}$} \\
\hline & & & Loading & & Loading & & Loading & & Loading & \\
\hline & Factor 1 & $\begin{array}{l}\text { Comm } \\
\text { unality }\end{array}$ & Factor 1 & $\begin{array}{l}\text { Comm } \\
\text { unality }\end{array}$ & Factor 1 & $\begin{array}{l}\text { Comm } \\
\text { unality }\end{array}$ & Factor 1 & $\begin{array}{l}\text { Comm } \\
\text { unality }\end{array}$ & Factor 1 & $\begin{array}{l}\text { Comm } \\
\text { unality }\end{array}$ \\
\hline \multicolumn{11}{|l|}{$\begin{array}{l}\text { External Market Sources of } \\
\text { Information: }\end{array}$} \\
\hline Suppliers & 0.451 & 0.203 & & & & & & & & \\
\hline Customers & 0.543 & 0.295 & & & & & & & & \\
\hline Competitors & 0.599 & 0.359 & & & & & & & & \\
\hline Consultants & 0.675 & 0.456 & & & & & & & & \\
\hline \multicolumn{11}{|l|}{ External Institutional } \\
\hline \multicolumn{11}{|l|}{ Sources of Information: } \\
\hline Universities & 0.753 & 0.567 & & & & & & & & \\
\hline Research Institutes & 0.744 & 0.554 & & & & & & & & \\
\hline \multicolumn{11}{|l|}{$\begin{array}{l}\text { External Other Sources of } \\
\text { Information: }\end{array}$} \\
\hline Conferences & 0.784 & 0.615 & & & & & & & & \\
\hline Publications & 0.804 & 0.646 & & & & & & & & \\
\hline Professional Associations & 0.804 & 0.646 & & & & & & & & \\
\hline Internet & 0.620 & 0.384 & & & & & & & & \\
\hline IS as a Dpt. of the Firm & & & 0.729 & 0.531 & & & & & & \\
\hline R\&D as a Dpt. of the Firm & & & 0.763 & 0.582 & & & & & & \\
\hline Eng. as a Dpt. of the Firm & & & 0.752 & 0.565 & & & & & & \\
\hline $\begin{array}{l}\text { The Firm launched a new } \\
\text { product in } 2014\end{array}$ & & & & & 0.844 & 0.712 & & & & \\
\hline $\begin{array}{l}\text { The Firm launched a new } \\
\text { service in } 2014\end{array}$ & & & & & 0.844 & 0.712 & & & & \\
\hline \multicolumn{11}{|l|}{ Marketing Innovation in: } \\
\hline Packaging & & & & & & & 0.841 & 0.708 & & \\
\hline Advertising & & & & & & & 0.924 & 0.854 & & \\
\hline Distribution & & & & & & & 0.921 & 0.848 & & \\
\hline Pricing & & & & & & & 0.866 & 0.749 & & \\
\hline \multicolumn{11}{|l|}{ Process and Org. } \\
\hline \multicolumn{11}{|l|}{ Improvement in: } \\
\hline Manufacturing & & & & & & & & & 0.741 & 0.550 \\
\hline Logistics & & & & & & & & & 0.820 & 0.673 \\
\hline Support & & & & & & & & & 0.840 & 0.706 \\
\hline Process Design & & & & & & & & & 0.918 & 0.843 \\
\hline Decision Making & & & & & & & & & 0.913 & 0.834 \\
\hline External Relations & & & & & & & & & 0.854 & 0.729 \\
\hline $\begin{array}{l}\text { Eigenvalue } \\
\% \text { of Total Variance }\end{array}$ & $\begin{array}{l}4.726 \\
90\end{array}$ & & $\begin{array}{l}1.678 \\
121\end{array}$ & & $\begin{array}{l}1.424 \\
113\end{array}$ & & $\begin{array}{l}1.678 \\
121\end{array}$ & & $\begin{array}{l}4.335 \\
96\end{array}$ & \\
\hline
\end{tabular}




\section{Control Variables}

Potential confounding effects were controlled for by including various relevant sets of variables. Because large companies may lack the flexibility to explore even though they might have more resources, company size in terms of sales was included as a variable. Company age was included as the logarithm of the number of years from its founding since previous studies have shown that aging companies are more likely to develop innovation that exploits existing competencies (Sørensen \& Stuart, 2000).

Diversity in organizational tenure could affect strategic organizational changes (Milliken \& Martins, 1996). Therefore, the logarithms of the number of workers in three distinct areas (i.e., engineering, information systems, and R\&D) are used as proxies of diversity.

Companies are likely to apply their existing in-depth knowledge to customer groups and geographic regions that are similar to those they already serve. The application of this in-depth knowledge could result in exploitative innovation (van Wijk et al., 2012). Therefore, the model is controlled for the geographic region; in the case of Chile, there are 15 geographic regions.

Some industry sectors are more exposed to technology changes than others. As a result, companies in these sectors are more prone to engage in innovation activities. Furthermore, companies acting in more than one sector could create economies of scope for internal resources (Wales et al., 2013). Industries with participation of more than $5 \%$ in the sample are included as control variables, i.e., manufacturing, wholesale and retail, construction, transportation, and healthcare. 
Additionally, increasing levels of education may relate positively to the employee ambidexterity since the higher the education level, the greater the cognitive abilities for processing information and learning (Adler, Goldoftas, \& Levine, 1999; Papadakis, Lioukas, \& Chambers, 1998). Educational levels were controlled by including a dummy variable reflecting employees with master's degrees. Employees with lower than the master's degrees were the reference group.

Companies with R\&D capabilities in-house could be less aggressive in reaching outside the boundaries of their organizations for new knowledge. This dichotomous variable, part of the questionnaire, is included as a control variable. In the same manner, internal innovation efforts could have different effects on the organization, which is measured in the questionnaire and included as a control variable with three distinct impact levels, where zero impact is the reference measure.

\section{Statistical Methods}

A multivariate regression model is used to analyze the relationship between strategic absorptive capacity and operational absorptive capacity (i.e., the independent variables) and exploration, incremental exploitation, and repetitive exploitation (i.e., the dependent variables). A multiple analysis of variance test is performed prior to the multivariate regression model to test whether or not the independent grouping variable simultaneously explains a statistically significant amount of variance in the dependent variables. The Wilk's Lambda U test, the Lawley-Hotelling test, the Pillai test, and Roy's Largest Root test are performed. 
Additionally, factor analyses are conducted using the polychoric correlation matrix in all cases since the underlying variables were all dichotomous (Netter, Wasserman, \& Kutner, 1990).

\section{Results}

\section{Main Results}

Table 2.2 shows descriptive statistics and correlations for all variables. Most variables show low to very little correlation except for those depicting company size, which shows a moderate correlation factor of 0.515 , slightly larger than 0.5 .

Table 2.3 presents the results of the multivariate regression analyses for the interaction between absorptive capacity and organizational ambidexterity. The baseline models (Model 1 for the three dependent variables) contain control variables. Model 2 includes the independent variables' strategic absorptive capacity and operational absorptive capacity. Regarding the effects of absorptive capacity on organizational ambidexterity, Model 2 shows that strategic absorptive capacity has a positive and significant influence on exploration at the firm $(\beta=0.032, \mathrm{p}<0.05)$, and therefore, $\mathrm{H} 1$ is supported. The analysis shows that strategic absorptive capacity also has a positive and significant influence on incremental exploitation at the firm $(\beta=$ 0.070, $\mathrm{p}<0.01$ ), supporting H2. Model 2 also shows that operational absorptive capacity has, simultaneous with strategic absorptive capacity, a positive and considerable influence on incremental exploitation $(\beta=0.088, \mathrm{p}<0.05)$, validating H3. Finally, the model shows that operational absorptive capacity has a positive and considerable influence on repetitive exploitation $(\beta=0.092, \mathrm{p}<0.05)$, validating H4. Thus, our findings indicate that absorptive capacity has a direct and positive influence 
on organizational ambidexterity. Moreover, the model shows that strategic absorptive capacity influences exploration as well as incremental exploitation at the firm level. Another relevant finding is that operational absorptive capacity also influences incremental exploitation as well as repetitive exploitation. 


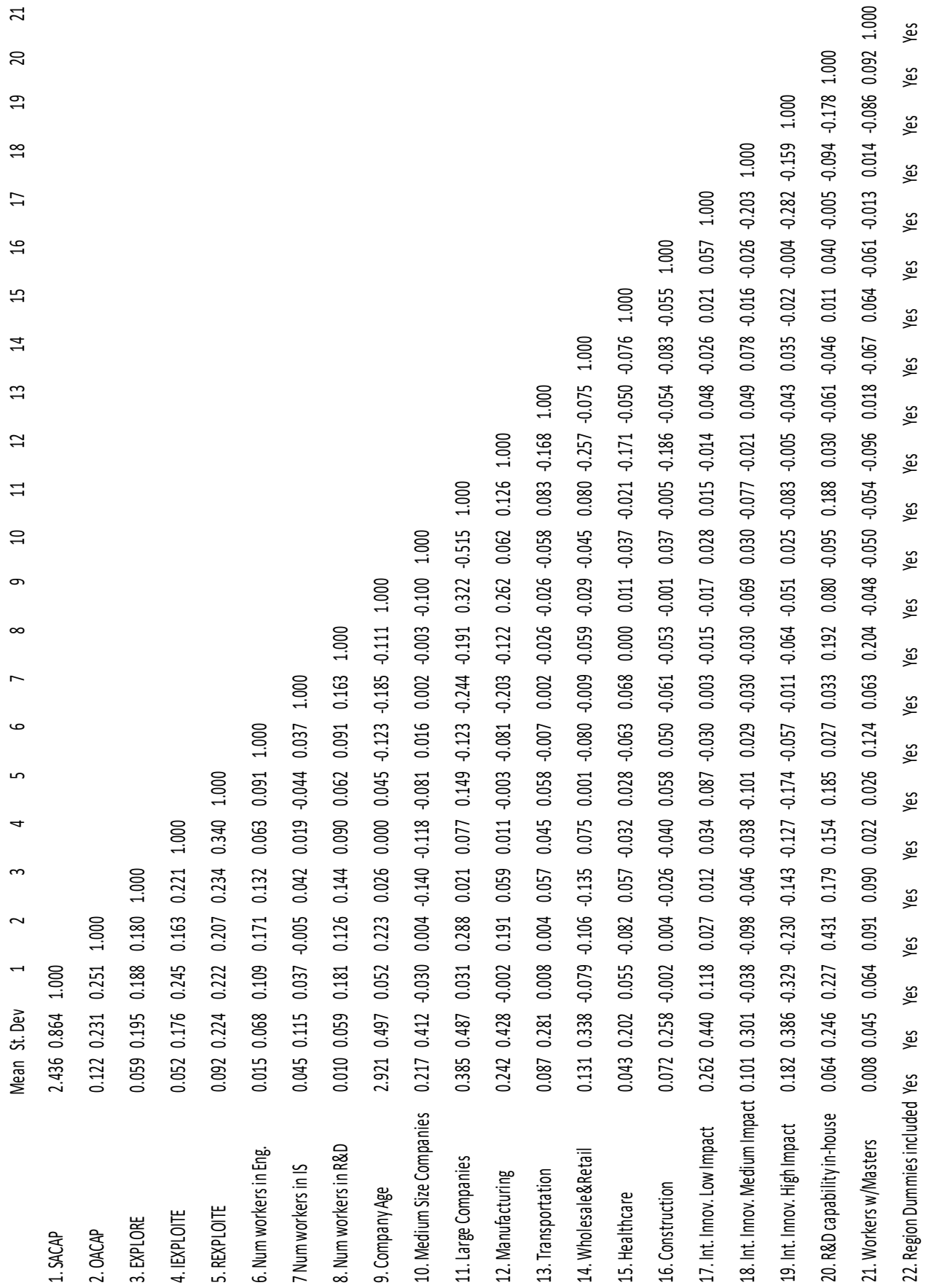




\begin{tabular}{|c|c|c|c|c|c|c|}
\hline & \multicolumn{2}{|l|}{$\begin{array}{l}\text { Exploration } \\
(\text { EXPLORE) }\end{array}$} & \multicolumn{2}{|c|}{$\begin{array}{l}\text { Incremental Exploitation } \\
\text { (IEXPLOITE) }\end{array}$} & \multicolumn{2}{|c|}{$\begin{array}{l}\text { Repetitive Exploitation } \\
\text { (REXPLOITE) }\end{array}$} \\
\hline & Model 1 & Model 2 & Model 1 & Model 2 & Model 1 & Model 2 \\
\hline \multicolumn{7}{|l|}{$\begin{array}{l}\text { Effects of Absorptive Capacity on } \\
\text { Ambidexterity (IVs) }\end{array}$} \\
\hline $\begin{array}{l}\text { Strategic Absorptive Capacity }(S A C A P) \mathrm{H} 1 \text { and } \\
\mathrm{H} 2\end{array}$ & & \multirow[t]{3}{*}{$\begin{array}{l}0.032 * \star \\
(0.012)\end{array}$} & & \multirow{3}{*}{$\begin{array}{l}0.070 * * * \\
(0.012) \\
0.088 * \star \\
(0.035)\end{array}$} & & \\
\hline $\begin{array}{l}\text { Operational Absorptive Capacity }(O A C A P) \mathrm{H} 3 \\
\text { and H5 }\end{array}$ & & & & & & $\begin{array}{l}0.092 \star \star \\
(0.037)\end{array}$ \\
\hline Control Variables & \multirow{5}{*}{$\begin{array}{l}0.021 \\
(0.022) \\
-.137 \star \star \star \\
(0.030) \\
-0.055 * \star \\
(0.026)\end{array}$} & & & & & \\
\hline Company Age & & \multirow{4}{*}{$\begin{array}{l}0.010 \\
(0.022) \\
-.152 \star * \star \\
(0.031) \\
-.074 * * \star \\
(0.028)\end{array}$} & \multirow{4}{*}{$\begin{array}{l}-0.020 \\
(0.021) \\
-0.081 * \star \star \\
(0.029) \\
-0.003 \\
(0.025)\end{array}$} & \multirow{4}{*}{$\begin{array}{l}-0.035^{\star} \\
(0.021) \\
-0.096^{\star \star \star} \\
(0.029) \\
-0.024 \\
(0.026)\end{array}$} & \multirow{4}{*}{$\begin{array}{l}-0.013 \\
(0.022) \\
-0.005 \\
(0.030) \\
-.069 * \star \star \\
(0.026)\end{array}$} & \multirow{4}{*}{$\begin{array}{l}-0.026 \\
(0.022) \\
-0.021 \\
(0.031) \\
-0.047 \star \\
(0.027)\end{array}$} \\
\hline Company Size-M & & & & & & \\
\hline Company Size-L & & & & & & \\
\hline Industry Sectors: & & & & & & \\
\hline Manufacturing & \multirow{6}{*}{$\begin{array}{l}0.067 * \star \star \\
(0.025) \\
0.125 * \star * \\
(0.049) \\
-0.071 * \star \\
(0.035) \\
0.106 * \star \\
(0.048) \\
-0.009 \\
(0.045)\end{array}$} & \multirow{6}{*}{$\begin{array}{l}0.059 * * \\
(0.025) \\
0.121 * \star \\
(0.049) \\
-0.064 * \\
(0.035) \\
0.106 * \star \\
(0.048) \\
-0.009 \\
(0.045)\end{array}$} & \multirow{6}{*}{$\begin{array}{l}0.041 * \\
(0.023) \\
0.099 * \star \\
(0.047) \\
0.106 * \star \star \\
(0.034) \\
-0.023 \\
(0.045) \\
-0.022 \\
(0.043)\end{array}$} & \multirow{6}{*}{$\begin{array}{l}0.033 \\
(0.023) \\
0.093 \star \star \\
(0.046) \\
0.117 \star \star \star \\
(0.033) \\
-0.032 \\
(0.045) \\
-0.021 \\
(0.042)\end{array}$} & \multirow{6}{*}{$\begin{array}{l}0.019 \\
(0.024) \\
0.113 \star \star \\
(0.049) \\
0.045 \\
(0.035) \\
0.068 \\
(0.048) \\
0.081 \star \\
(0.045)\end{array}$} & \multirow{6}{*}{$\begin{array}{l}0.011 \\
(0.024) \\
0.108 * \star \\
(0.048) \\
0.054 \\
(0.035) \\
0.064 \\
(0.047) \\
0.081 \star \\
(0.044)\end{array}$} \\
\hline Transport and Communications & & & & & & \\
\hline Wholesale and Retail & & & & & & \\
\hline Healthcare & & & & & & \\
\hline Construction & & & & & & \\
\hline Number of workers per Dpt.: & & & & & & \\
\hline Engineering & \multirow{4}{*}{$\begin{array}{l}0.428 * \star \star \\
(0.119) \\
0.034 \\
(0.087) \\
0.334 * \star \star \\
(0.126)\end{array}$} & \multirow{4}{*}{$\begin{array}{l}0.334 * * \star \\
(0.122) \\
0.010 \\
(0.087) \\
0.256 * \star \\
(0.127)\end{array}$} & \multirow{4}{*}{$\begin{array}{l}0.224 * * \\
(0.113) \\
0.022 \\
(0.082) \\
0.239 * * \\
(0.120)\end{array}$} & \multirow{4}{*}{$\begin{array}{l}0.096 \\
(0.114) \\
-0.005 \\
(0.081) \\
0.111 \\
(0.119)\end{array}$} & \multirow{4}{*}{$\begin{array}{l}0.366 * * \star \\
(0.119) \\
-0.099 \\
(0.086) \\
0.204 * \\
(0.125)\end{array}$} & \multirow{4}{*}{$\begin{array}{l}0.249 \star \star \\
(0.121) \\
-0.125 \\
(0.086) \\
0.098 \\
(0.126)\end{array}$} \\
\hline Information Systems & & & & & & \\
\hline R\&D and Innovation & & & & & & \\
\hline Internal sources of Innovation: & & & & & & \\
\hline Low Importance & \multirow{6}{*}{$\begin{array}{l}-0.020 \\
(0.024) \\
-0.059 * \\
(0.035) \\
-.103 * * * \\
(0.028) \\
0.086 * * * \\
(0.022) \\
0.127 \\
(0.195) \\
1,011\end{array}$} & \multirow{5}{*}{$\begin{array}{l}-0.021 \\
(0.024) \\
-0.048 \\
(0.035) \\
-0.072 * \star \\
(0.029) \\
0.060 * \star \\
(0.024) \\
0.107 \\
(0.194)\end{array}$} & \multirow{5}{*}{$\begin{array}{l}-0.002 \\
(0.023) \\
-0.056 * \\
(0.033) \\
-0.085 * \star \star \\
(0.027) \\
0.077 * \star \star \\
(0.021) \\
-0.106 \\
(0.185)\end{array}$} & \multirow{5}{*}{$\begin{array}{l}-0.004 \\
(0.023) \\
-0.038 \\
(0.032) \\
-0.031 \\
(0.028) \\
0.041^{\star} \\
(0.022) \\
-0.112 \\
(0.182)\end{array}$} & \multirow{5}{*}{$\begin{array}{l}0.014 \\
(0.024) \\
-.111 * \star \star \\
(0.034) \\
-.125 * \star \star \\
(0.028) \\
0.082 \star \star \star \\
(0.022) \\
-0.068 \\
(0.194)\end{array}$} & \multirow{5}{*}{$\begin{array}{l}0.012 \\
(0.024) \\
-.096 * \star \star \\
(0.034) \\
-.081 * \star \star \\
(0.029) \\
0.049 * \star \\
(0.023) \\
-0.085 \\
(0.192)\end{array}$} \\
\hline Medium Importance & & & & & & \\
\hline High Importance & & & & & & \\
\hline R\&D capability in-house & & & & & & \\
\hline Percentage of workers w/Masters degrees & & & & & & \\
\hline $\mathrm{N}$ & & 1,011 & 1,011 & 1,011 & 1,011 & 1,011 \\
\hline RMSE & 0.310 & 0.309 & 0.295 & 0.289 & 0.309 & 0.305 \\
\hline $\mathrm{R}^{2}$ & 0.126 & $\begin{array}{l}0.138 \\
0.161\end{array}$ & 0.077 & $\begin{array}{l}0.117 \\
1.331\end{array}$ & 0.110 & $\begin{array}{l}0.130 \\
0.610\end{array}$ \\
\hline
\end{tabular}




\section{Robustness Tests}

Next, several robustness checks are conducted to validate Models 1 and 2. Eight sets of control variables as described above were introduced to avoid a confounding effect on both models. Adding the independent variables explains an additional $7 \%$ over Model 1 results. To evaluate heteroscedasticity and multicollinearity on the models, a run was performed with robust standard errors, and variance inflation factors were calculated for each dependent variable. In all cases, the influence of the variables was

significant at the $1 \%$ level, and all factors were lower than 2.0 , well below the rule-ofthumb cutoff of 10 (Netter et al., 1990).

Several data subsets were run to determine if they had more explanatory power than the original data set. A run with only manufacturing firms resulted in strategic and operational absorptive capacity not being significant for exploration and repetitive exploitation. The same behavior is observed when the run is only on firms located in region 13 (i.e., Santiago, Chile's capital city), in which strategic absorptive capacity is not significant for exploration.

In a meta-analysis on organizational ambidexterity and performance, Junni et al. (2013) discuss the different approaches taken by researchers measuring ambidexterity. When exploration and exploitation are combined, ambidexterity has been represented as the addition or multiplication of exploration and exploitation. For this study's robustness check, a single dependent variable representing ambidexterity was used, replacing EXPLORE, IEXPLOITE, and REXPLOITE. Since the extant research has not addressed the separation between incremental and repetitive exploitation, a combination of EXPLORE is assumed as adding or multiplying a single 
variable, EXPLOITE, defined as the multiplication of IEXPLOITE and REXPLOITE. In both instances, representing the combination as an addition or multiplication, the explanatory power of analyzing the three separate variables is higher than the single variable, i.e., $R^{2}$ of 0.113 vs. 0.385 for the product, and $R^{2}$ of 0.183 vs. 0.385 for the sum. A similar result is obtained when replacing the strategic absorptive capacity variable with a proxy represented by whether or not companies have an outsourced R\&D function. Finally, additional control variables are included representing doctoral and technical education levels, resulting in no significant changes to the results.

\section{Discussion and Conclusions}

I began this study by introducing a gap in the literature regarding the direct relationship between absorptive capacity and organizational ambidexterity. The current business environment requires companies to reach out for new ideas, technologies, and best practices in order to maintain their competitive advantages. The original definition of ambidexterity posed a dichotomy between exploration and exploitation, assimilating the former with R\&D and radical innovation, and the latter with operational efficiency (March, 1991). A significant spectrum between both positions existed that was not captured by initial studies of the construct. In agreement with Piao and Zajac (2016), and closer to the actual organizational innovation practices, with which companies conducting radical innovation usually perform incremental innovation as a portfolio effort, I differentiate exploitation between incremental exploitation, associated with incremental innovation and repetitive exploitation, associated with operational efficiency. 
Organizations have always reached out for new knowledge or best practices, regardless of whether they were related to operations or new competitive advantages. Instead of treating absorptive capacity as a phenomenon exclusively in the realm of innovation or operations as the extant literature suggests, this study combines the observation of both research streams into a construct with two elements, a strategic absorptive capacity, related to innovation and operational absorptive capacity related to innovation as well as operational efficiency.

Focusing on firm-level entities, the objective of this study is to understand how the absorptive capacity at the strategic and operational levels affects organizational ambidexterity. Piao and Zajac (2016) have explored this relationship but only at the strategic level of absorptive capacity and based on one case study, lacking generalizability. This study's findings are consistent with those of Piao and Zajac, showing a positive relationship between strategic absorptive capacity and exploration. More relevantly, this study demonstrates the positive impact of both strategic absorptive capacity and operational absorptive capacity on incremental exploitation. This finding indicates that the effort of improving existing products, services, and processes is better served with contributions from innovative and operational external knowledge. Additionally, as expected from the extant operational literature, the study finds that operational absorptive capacity has a positive impact on repetitive exploitation.

This study contributes to the understanding of the different dimensions of organizational ambidexterity, particularly with the validation of Piao and Zajac's model of incremental and repetitive exploitation. These authors proposed their hypothesis based on a single company case study; this analysis contributes to the 
generalizability of the proposed model through its validation over a data set of more than 1,000 companies of varied sizes across several industries. The proposed model of absorptive capacity that includes an innovative and operational dimension simultaneously is novel and contributes to the knowledge of this construct. Moreover, since absorptive capacity as an antecedent of ambidexterity has not been studied extensively before, this study contributes to theory by validating the hypothesis of the influence of innovative and operational absorptive capacity on incremental exploitation.

Additionally, managers tend to treat innovation knowledge separately from operational or efficiency best practices. This study shows that the simultaneous application of both types of knowledge contributes positively to the incremental innovation within the firm. This finding will allow management to become more successful in its overall innovative efforts.

Despite the positive results, several limitations of the study could be accounted for in future research. Single-source bias is inherent to the study since the data was collected from one secondary source (Podsakoff \& Organ, 1986). Since the original survey is based on the OECD innovation questionnaire, further research, including data from other countries using the same standard, would be promising to overcome this bias. The analysis was conducted using only multivariate regression methodology; therefore common-method bias is present. It is suggested that other methodologies such as SEM, be used to overcome this limitation.

As mentioned above, since data were obtained from secondary sources, future research using ad hoc surveys could improve the understanding of the relationship between these constructs and overcome this limitation. 


\title{
CHAPTER 3
}

\section{THE ROLE OF STRATEGIC AND OPERATIONAL ABSORPTIVE CAPACITY IN ORGANIZATIONAL AMBIDEXTERITY - A}

\section{LONGITUDINAL STUDY}

\begin{abstract}
I have explored the relationship between strategic and operational absorptive capacity (SACAP and OACAP) and organizational ambidexterity in Chapter 2 and found a positive relationship between both constructs. In Chapter 3, I conduct a longitudinal study to explore the dynamic interaction between the constructs and the moderating effects of industry type (i.e. manufacturing vs. service), the collaborative nature of the firm, and policy changes over time. Using panel data from Chile's National Innovation Survey for the period 2009-2014, I find that the joint use of SACAP and OACAP increases both exploration and incremental exploitation. Additionally, absorptive capacity (ACAP) has a stronger positive effect on exploration when firms are in the service sector compared to firms in the manufacturing sector, as well as when firms are more collaborative. Contrary to my hypothesis, the passage of legislation that's geared towards promoting innovation does not increase firms' ACAP.

Chapter 3 makes three contributions to the literature on ACAP and ambidexterity. First, it provides a dynamic view of the relationship between ACAP and ambidexterity. Second, it sheds light on the moderating effects of industry type, collaborating practices, and innovation-incentive legislation. Third, the research shows a substantial increase in the positive impact of ACAP on exploration when SACAP and OACAP act together. From a managerial perspective, this study
\end{abstract}


highlights the importance of alliances to knowledge acquisition and the need for managers to conduct SACAP and OACAP simultaneously. For service firms, ACAP is effective at higher levels than for manufacturing firms. Finally, this study contributes to the assessment of the effectiveness of innovation-related public policies.

\section{Introduction}

The literature review in Chapter 2 shows substantial gaps in the literature on absorptive capacity (ACAP) and its effects on the exploratory and exploitative abilities of the firm. Motivated by these gaps in the literature, I posed the following question: How do strategic and operational absorptive capacity affect organizational ambidexterity? In Chapter 2 of this dissertation, I explored the relationship between a firm's absorptive capacity and organizational ambidexterity by focusing on two levels of absorptive capacity and three dimensions of organizational ambidexterity. Drawing upon organizational learning literature and operational management theories, I introduced a multi-level absorptive capacity construct. It includes a strategic element based on Cohen and Levinthal (1990) and is defined as the ability of top management to recognize and interpret the opportunity of external innovations. It also has an operational element defined by Patel et al. (2002) as “the ability of a firm's operational unit to acquire, assimilate, transform and exploit knowledge from the operations environment" (p. 202).

Consistent with the hypotheses outlined in Chapter 2, both strategic and operational absorptive capacity exert a positive influence on the exploration and repetitive exploitation dimensions of ambidexterity respectively. Concurrently, strategic and operational absorptive capacity also positively influence the ability of the 
firm to perform incremental innovation, otherwise defined by Piao and Zajac (2016) as incremental exploitation. The conclusions reached in Chapter 2 have managerial implications by providing theoretical grounds for the decision to reach outside the organization for new knowledge to enhance its exploratory and incremental exploitation capacities.

Notwithstanding the contributions reported in Chapter 2, these results have two limitations. First, it describes a static relationship between absorptive capacity and ambidexterity, which is far from complete. Studies of panel data from New Zealand and the UK have demonstrated that the impact of absorptive capacity on the firm's ability to innovate varies over time (Harris \& Moffat, 2011; Harris \& Moffat, 2013; Harris \& Le, 2018). An extensive literature covers this variation of ambidexterity over time and its impact on firm performance and innovation capacity (Ahuja \& Morris Lampert, 2001; Benner \& Tushman, 2003; Phelps, 2010; Uotila et al., 2009). Given the evidence of the time-changing nature of both constructs, a dynamic view is required to better understand their interaction.

Second, Chapter 2 does not explore the possible moderators that may affect the dynamic relationship between these two constructs. Comprehensive surveys conducted by the World Economic Forum (i.e. the Global Competitive Index) and INSEAD with Cornell University (i.e. the Global Innovation Index) coincide in concluding that government-sponsored private investments in $\mathrm{R} \& \mathrm{D}$ and joint ventures or strategic alliance deals are among the more influential factors in the innovation and competitive capabilities of companies (Dutta et al., 2016; Schwab \& Sala-i-Martin, 2018). Although these conclusions have been validated by academic studies (Mina et al., 2014; Phelps, 2010), little research has addressed how they affect the absorptive 
capacity and ambidexterity relationship. Moreover, there is a discrepancy in the literature regarding the use of absorptive capacity and its impact on ambidexterity by companies in the manufacturing versus service sectors. While Mina et al. (2014) and Arbussa and Coenders (2007) find that service sectors benefit more from absorptive capacity than manufacturing firms, Álvarez et al. (2015) find the opposite.

In Chapter 3, I further explore the relationship between these constructs over time and focus on the moderating effects of their industry sector (i.e., service vs. manufacturing), collaboration activities, and the influence of innovation-promoting legislation. Using a panel data set of 769 firms based on Chile's National Innovation Survey between the years 2009 and 2014, I find that relative to manufacturing firms, service-sector firms achieve a higher level of exploration for an increased level of absorptive capacity. These findings are consistent with those by Arbussa and Coenders (2007), but in contradiction with the results found by Álvarez et al. (2015). A similar pattern is found for the relationship between absorptive capacity and incremental exploitation. Further, this finding is in partial agreement with Geerts, Blindenbach-Driessen, \& Gemmel's (2010) conclusion that service firms seem to prefer incremental exploitation. Also, for the same level of increase in absorptive capacity, collaborative firms show $22 \%$ more influence on exploration than noncollaborative ones, but with diminishing returns for incremental effort on strategic absorptive capacity. So, a firm with absorptive capacity and engaged in collaboration should moderate the use of such capacity and only aim at the start of the diminishing return level. Furthermore, innovation incentive legislation is critical to understanding an ecosystem's early stages (Dutta et al., 2016). This study compares the efforts on absorptive capacity by Chilean companies prior to and after a substantial modification 
of innovation legislation aimed at increasing private firms' innovation activities. Contrary to the initial assumption (i.e., higher levels of absorptive capacity after the legislation was modified), I have observed a lower level of ACAP among firms. After a thorough analysis of the modified legislation, I conclude that, while probably unintended, the incentives promoted in-house rather than open innovation, thereby lowering firms' level of ACAP.

Chapter 3 makes three contributions to the literature on absorptive capacity and organizational ambidexterity. First, it provides a dynamic view of the relationship between absorptive capacity and ambidexterity, in line with the evidence reported by Harris and colleagues (Harris \& Moffat, 2011; Harris \& Moffat, 2013; Harris \& Le, 2018). These findings contribute to the theoretical understanding of the dynamics between on the one hand external sources of knowledge and innovation, and on the other hand the ambidextrous capability of the firm. Second, this study contributes to the understanding of the moderating effects of two relevant variables, industry type (i.e., service vs. manufacturing), and collaborating practices. The longitudinal study also sheds light on how innovation-incentive legislation impacts the dynamics between the constructs. Third, the research shows a substantially different interacting pattern of exploration and incremental exploitation with absorptive capacity: absorptive efforts show diminishing returns on exploration while demonstrating an always positive impact for incremental exploitation. From a managerial perspective, this study highlights the need for managers to seek external knowledge for innovative and operational purposes in a coordinated way, since the value added in exploration and incremental exploitation is larger than isolated efforts. Moreover, managers in 
service firms seeking outside knowledge must reach high levels of absorptive capacity to have a significant impact on their exploratory efforts, while manufacturing firms would be more efficient in their exploratory efforts than service firms at similar ACAP levels. Finally, this study helps to assess the effectiveness of public policies by evaluating innovation-incentive legislation and its impact on the relationship between absorptive capacity and ambidexterity.

Chapter 3's organization is as follows: I start with a literature review section that describes all relevant longitudinal studies on absorptive capacity and ambidexterity, the relevance of absorptive capacity on national-level innovation efforts, and the variation of relevant variables over the period under study in Chile. I then propose several hypotheses on the moderating effect of industry sector, the collaborative nature of the companies, and the exogenous effect of innovationincentive legislation. Next, I outline the empirical analysis and present the results. Finally, I discuss the implications of results and some directions for further research.

\section{Literature Review}

In a study conducted on New Zealand's firms, Harris and Le (2018) examine the effect of absorptive capacity on their productivity over a 10 -year period. The authors find that absorptive capacity has a substantial influence on exporting, innovation, and undertaking R\&D. They also find a general decline in absorptive capacity in manufacturing over time but not in the primary or service sectors. They conclude that it takes a considerable period to build or erode absorptive capacity, consistent with the dynamic capability literature (Helfat \& Peteraf, 2003; Helfat \& Winter, 2011; Teece, 2007). They also conclude that moving an average firm to the 
frontier value of each measure of absorptive capacity increases their ability to export and innovate.

Harris and Moffat (2013) propose a proxy of absorptive capacity based on five variables (i.e., business management and network, external knowledge, national cooperation, international cooperation, and global specialized knowledge) derived from a factor analysis performed on the UK's Community Innovation Survey data set for the period 2002-2004. Expanding on the previous study, Harris and Le (2018) conduct a longitudinal analysis based on the same survey but for the period 20042014. Using the same methodology, they identified the same five variables to operationalize the absorptive capacity construct but re-labeled "business management and network" as "business innovation" (i.e., external knowledge, national cooperation, international cooperation, specialized knowledge, and business innovation). Findings on absorptive capacity mobility throughout the period of analysis are consistent with those reported by Harris \& Le (2018) for New Zealand's firms. Those firms with low absorptive capacity remained at low levels, and those with high absorptive capacity remained at the same level throughout the ten-year period. This finding suggests that dynamic capabilities (i.e., absorptive capacity) take a long time to acquire or erode. The authors find that pushing the absorptive capacity of a median firm to the value that defined the start of the 99-percentile increases the probability of exporting, innovation, and $\mathrm{R} \& \mathrm{D}$ activities by $13.6,47.2$, and 40 percentage points in manufacturing, while international cooperation has a negligible effect.

Understanding the evolution of exploitation and exploration over time and their interaction is key for the long-term sustainability of a firm. Many longitudinal studies have been conducted on the benefits of simultaneous (i.e., ambidexterity) vs. 
sequential mechanisms (Venkatraman, Lee, \& Iyer, 2007), and the risks of exploitation crowding out exploration; in other words, companies focused on efficiency at the expense of long-term adaptation (Benner \& Tushman, 2003). Consensus among the researchers is that regardless of whether the mechanisms are simultaneous or sequential, balancing both exploitation and exploration is the key element (Benner \& Tushman, 2003; Venkatraman et al., 2007). Some industries seem to favor one modality over the other as Geert et al. (2010) report on service sector preference for punctuated equilibrium (i.e., a sequential type) and manufacturing companies' preference for ambidexterity. Mina et al. (2014) report that service companies seem to use more external knowledge sources than manufacturing and they tend to collaborate more frequently with their customers and suppliers than their manufacturing counterparts. However, according to the authors, "the need remains to deepen our understanding of whether the search for external knowledge may indeed have different characteristics across the manufacturing and service sectors of the economy" (p. 855).

Both exploration and exploitation are affected by decisions taken by the company, such us entering into alliances and the nature of those alliances (Phelps, 2010), technology diversification (Quintana-García \& Benavides-Velasco, 2008), or exogenous conditions such us innovation tax incentives that significantly increase companies' spending in exploratory activities (Intelis, 2018).

Both the literature of absorptive capacity and exploration and exploitation show that longitudinal analysis is a very effective tool to demonstrate time-related phenomenon regarding rate of buildup in the case of absorptive capacity, the need for balanced exploration and exploitation activities within the firm to secure sustainability 
and key influencers in the performance of both constructs. However, there is no evidence in the literature of longitudinal analysis that would relate both constructs and analyze the consequences of the aforementioned factors in their interaction. Having established in Chapter 2 that there is a significant relationship between absorptive capacity and ambidexterity and that this relationship has managerial impact, I explore these gaps to better understand this relationship in Chapter 3.

\section{Conceptual Model and Hypotheses}

I use the same model developed in Chapter 2 as a base to validate the hypotheses proposed herein. First, based on the panel data of Chilean firms, I perform a verification of the validity of the conclusions reached in Chapter 2. Secondly, at the firm level and based on country-level evidence, I study other relevant variables to determine their impact on strategic and operational absorptive capacity and organizational ambidexterity. Finally, I explore the effect on ambidexterity of conducting strategic and operational absorptive capacities jointly.

Arbussa and Coenders (2007) study the differences in the absorptive capacity requirements between manufacturing and service firms. Using a similar instrument to the Chilean National Innovation Survey applied to Spanish firms, the authors conclude that manufacturing firms tend to perform in-house $R \& D$ and innovation activities, while service firms reach outside for recent technology. These findings agree with those reported by Harris and Le (2018). With a similar focus on manufacturing and service organizations, but investigating ambidexterity, Geerts et al. (2010) find that the latter favor ambidexterity while the former favor punctuated equilibrium. After a case study analysis, the authors conclude that service firms could 
wait and not invest in radically new capabilities until a later stage when opportunities are more apparent. Moreover, the authors emphasize that service firms seem to prefer incremental exploitation by creating value for their customers and improving efficiency in service delivery.

Other authors (Mina, Bascavusoglu-Moreau, \& Hughes, 2014; Tether \& Howells, 2007) find that, for developed countries, the propensity for technological innovation in service firms is lower than that for manufacturing innovation. Service firms are more likely to innovate in organizational change than are firms in the manufacturing sector. However, these conclusions are not homogeneous across the service industry. Knowledge-intensive business services are found to have similar levels of technological innovations as manufacturing firms while traditional service sectors tend to lean more towards non-technological innovation (i.e., marketing, organization, processes). In contrast, Álvarez et al. (2015) study Chile's fifth and sixth National Innovation Survey (2005-2008) and find that there is no significant difference between manufacturing and service industries in the probability of introducing innovations. The authors found that "while being significantly less exportoriented, the service sector shows very similar behavior to the manufacturing sector in innovation inputs, outputs, and productivity determinants and in both technological and non-technological innovation" (p. 609).

The substantial evidence that both manufacturing and service industries engage in innovation activities at a different rate is in apparent contradiction to the findings by Álvarez et al. (2015) for the Chilean market. With a broader data set for the Chilean case, spanning more and recent years, this research aims at clarifying this contradiction. Therefore, the following hypotheses are proposed: 
H1: The relationship between strategic absorptive capacity and exploration is stronger for service firms than for manufacturing firms.

H2: The relationship between strategic absorptive capacity and incremental exploitation is stronger for service firms than for manufacturing firms.

For the last twenty-five years, firms have been migrating from an internal-only R\&D model to a more open, collaborative model. Firms realized that it was not efficient to try to develop all the necessary knowledge in-house, particularly for those operating in high-technology industries due to the velocity of technological changes (Chesbrough, 2006; de Jong \& Freel, 2010; Santamaría, Nieto, \& Barge-Gil, 2009). There is also evidence that external collaboration influences innovation performance following a curvilinear (i.e., inverted U-shape) relationship (Laursen and Salter, 2006).

There is substantial evidence supporting the impact of network participation on innovation as presented by Fukugawa (2006) for small businesses engaged in knowledge sharing and R\&D cooperation, and for cross-industry groups as reported by de Jong and Freel (2010). Fukugawa and de Jong and Freel coincide in concluding that collaboration drives joint product development and successful innovation commercialization. Lavie and Rosenkopf (2006) associate absorptive capacity exclusively with exploration, they recognize that ACAP "motivates the search for new technologies and the assimilation of external knowledge" inferring that this practice facilitates the formation of $R \& D$ alliances (p. 802). The pursuit of external knowledge, according to the authors, motivates firms to identify new and characteristically different partners in different domains, but they acknowledge that path-dependent absorptive capacity might slow down balancing exploration and 
exploitation within a specific domain. In a related study, Lavie (2006) allocates a significant role to absorptive capacity in capturing spill over rent from shared and non-shared resources of an alliance partner.

Innovation networks with absorptive capacity emerge as a result of dynamic collaboration between firms with complementary knowledge. This is especially the case for young industries with limited involuntary but abundant voluntary spillover. Absorptive capacity plays a key role in the presence of networks with voluntary spillover (Savin \& Egbetokun, 2016). Collaboration is also considered a double-edged sword due to the danger of exposing proprietary knowledge and involuntary spillover. This is a problem faced by multinational corporations (MNC) in selecting the location of their R\&D facilities. Feinberg and Gupta (2004) report that MNCs appear to anticipate potential spillover opportunities across locations and incorporate this factor along with the more traditional host country factor endowments. In a study on the relationship between R\&D spillovers and R\&D cooperation, Cassiman \& Veugelers (1998) conclude that protection against outgoing spillovers is important for firms engaged in long-term collaboration by reducing free-rider problems. The effectiveness of alliances, according to these authors, is influenced by the investment allocation and cognitive distance between partners; both factors determine absorptive capacity. Investment allocation requires a trade-off between the creation of a firm's knowledge and the improvement of its absorptive capacity. Alliances require reciprocal and voluntary spillovers, therefore constituting a benefit but also a potential risk. Thus, firms seeking alliances will pay attention not only to the knowledge they could gain but also to the partner's absorptive capacity. 
A more extreme situation arises with firms that simultaneously cooperate and compete; in a review of the state of the art of competition, Hoffmann, Lavie, Reuer, and Shipilov (2018) identify that in horizontal alliances between competitors, a learning race could result in knowledge leakage that alters their relationship. The authors recognize that in a learning alliance, such leakage could enable a firm to develop independent capabilities that in turn will be used to compete with its former partner in a subsequent period.

As shown in the previous paragraphs, there is substantial evidence in the literature that alliances improve the knowledge of participating firms. Successful alliances require a balanced allocation of resources between a firm's knowledge creation and the build-up of absorptive capacity; too much unbalance towards absorptive capacity and the free-rider effect will be perceived by the partner. If a firm has too little absorptive capacity, it will be unable to explore the knowledge available from the partnership. Given the fact that alliances imply voluntary spillover of knowledge, it is reasonable to infer that firms that rely only on involuntary spillovers from the market develop a stronger strategic absorptive capacity for a same level of exploration than those firms that enjoy such voluntary spillovers from collaborating activities. It is also the case that companies with strong in-house strategic absorptive capacity are less dependent on collaboration spillovers; thus, the former is acting as a substitute of the latter. When it comes to exploitation, the strategic absorptive capacity exercised by collaborating firms is considered necessary due to the velocity of technological changes (Chesbrough, 2006). Therefore, the following hypotheses are proposed: 
H3: The relationship between strategic absorptive capacity and exploration is weaker for collaborative than for non-collaborative firms.

H4: The relationship between strategic absorptive capacity and incremental exploitation is stronger for collaborative than for non-collaborative firms.

In 2008, Chile introduced legislation to incentivize R\&D and innovation at the firm level. Specifically, firms were allowed $35 \%$ of innovation expenses as a tax credit and the remainder as tax deductible (Intelis, 2018; OECD, 2018). At the time, companies were required to collaborate with universities or research institutions as a requisite to access the benefits, and thus the companies rarely utilized the legislation. In 2012 a modification to the legislation was introduced, allowing firms a broader menu of incentive tools, lifting the external collaboration requirement. The norm allowed for external as well as internal $R \& D$ initiatives and recognized innovation operational and capital expenses (Intelis, 2018). This change in the legislation generated a significant change in firms' behavior with an increase in claimed tax credits and benefits between 2012 and 2015 of eightfold as shown in Figure 3.6 (Intelis, 2018). The effect of tax incentives in $R \& D$ and innovation $(R \& D+i)$ has been extensively studied, and there is evidence that $1 \%$ increment in private $\mathrm{R} \& \mathrm{D}+\mathrm{i}$ expenditure increases a country's productivity growth by $0.13 \%$ (Guellec \& van Pottelsberghe de la Potterie, 2002).

Government support policies for innovation impact not only productivity at the macro level, but also the degree of openness of individual firms in terms of number of external partners and the number of open innovation activities performed. Based on an analysis of more than 5,000 companies in 29 European countries, Cano-Kollmann, 
Hamilton, \& Mudambi (2016) reach these conclusions not only for monetary but for non-monetary policies as well.

The results presented indicate that incentive policies, at least in Europe, are designed to enhance open innovation activities at the firm level. Value creation through open innovation activities is closely related to the ability of the firm to identify and successfully incorporate new external knowledge (i.e., absorptive capacity).

The explosive increase of tax credit uses by Chilean firms starting in 2012 indicate that Chilean firms are engaging in innovation activities through governmentled incentive policies. Following Cano-Kollmann et al.'s conclusions, one should expect a significant increase in open innovation activities by the companies. Inherent to open innovation is the notion of reaching outside the organization for new knowledge. Many studies have recognized absorptive capacity as an open innovation key capability going as far as stating that absorptive capacity is a pre-condition to the implementation of open innovation (Spithoven, Clarysse, \& Knockaert, 2011). Therefore, an increase in absorptive capacity should be observed with a positive impact on exploration and incremental exploitation. For the comparative analysis, and due to the fact, that prior to 2012, the existing incentive legislation was scarcely used, I assume incentive legislation to have started in 2012. Therefore, I propose the following hypothesis:

H5: The relationship between strategic absorptive capacity and exploration is stronger with firm-centered $R \& D+i$ incentive legislation than without such legislation. 
H6: The relationship between strategic absorptive capacity and incremental exploitation is stronger with firm-centered $R \& D+i$ incentive legislation than without such legislation.

Figure 3.1 provides an overview of the proposed model in which all constructs and hypotheses are listed.

\section{Empirical Analysis}

\section{Data Sample and Data Sources}

I use secondary data available from the Chilean National Innovation Survey of the National Institute of Statistics from 2009 to 2014 to test my hypotheses. This survey, performed at the firm level, follows the OECD guidelines included in the Oslo Manual (Organisation for Economic Co-operation and Development, 1997). Chile has been conducting this survey for nine consecutive years since its National Innovation Strategy was introduced in 2006. Approximately 5,000 companies participate in each national survey, though without continuity. The National Statistical Institute of Chile has cleaned the database and identified a data set of 769 companies that participated in all six surveys for the 2009-2014 period. This data set is used for my research.

The 2009-2014 surveys cover the entire country at the firm level, classified by their economic activity using the International Standard Industrial Classification (United Nations, 2004). The sampling is stratified on two levels: economic activity and company size. Small companies are defined as those with sales at or less than $\$ 1.0$ $\mathrm{mm}$; medium-sized companies are those with sales at more than $\$ 1.0 \mathrm{~mm}$, but less than $\$ 4.0 \mathrm{~mm}$, and large companies are defined as those selling more than $\$ 4.0 \mathrm{~mm}$. Companies with sales lower than $\$ 0.1 \mathrm{~mm}$ are excluded from the study. The database is restricted in that the confidentiality of the companies is protected by assigning a 


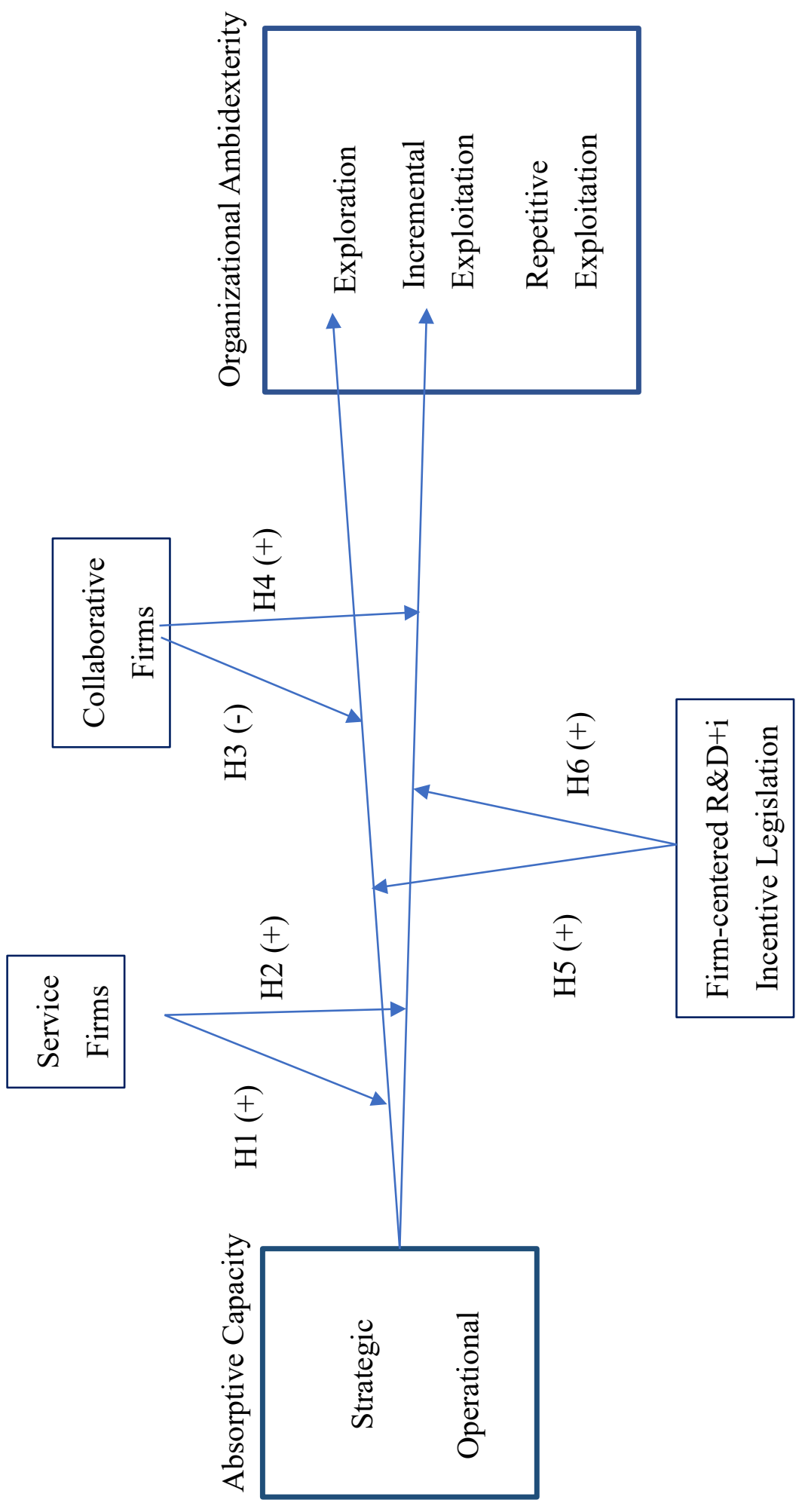

Figure 3.1 Moderators to the Absorptive Capacity and Ambidexterity relationship 
unique code to each participant and no information will be disclosed to help identify the firms.

In the data sample, the average age of the responding firms is 30 years with a standard deviation of 21.19 years. The average size, measured as the number of employees, is 658 with a standard deviation of 2530 workers. The large standard deviation is driven by ten companies that have an extremely large number of employees (more than 10,000 employees) in the data set.

\section{Independent Variables}

Strategic absorptive capacity was derived from a factor analysis conducted on a set of questions from the survey addressing the external sources firms reached out to for purposes of their innovation activities. Since the questions do not identify the type of activity that the external sources impact upon (i.e., exploratory or exploitative), it is assumed that all sources selected by the survey participants refer exclusively to innovation and not operations within the firm. Therefore, all external sources included in the survey are considered proxies of the strategic absorptive capacity: they are classified as market (i.e., suppliers, customers, competitors, and consultants), institutional sources (i.e., universities and research facilities), and others (i.e., conferences, publications, professional associations, and the internet). Answers to these ten questions were dichotomous (YES/NO). Capital expense allocated to new equipment related to innovation was also included in the construct. A polychoric procedure was conducted before the factor analysis. The results were rotated for a better fit, and the factors with an eigenvalue higher than 1.0 were retained. Table 3.1 


\begin{tabular}{|c|c|c|c|c|c|c|c|c|c|c|}
\hline \multirow[b]{3}{*}{ Survey Item } & \multicolumn{2}{|c|}{$\begin{array}{c}\text { Strategic } \\
\text { Absorptive } \\
\text { Capacity }\end{array}$} & \multicolumn{2}{|c|}{$\begin{array}{c}\text { Operational } \\
\text { Absorptive } \\
\text { Capacity }\end{array}$} & \multicolumn{2}{|c|}{ Exploration } & \multicolumn{2}{|c|}{$\begin{array}{l}\text { Incremental } \\
\text { Exploitation }\end{array}$} & \multicolumn{2}{|c|}{$\begin{array}{c}\text { Repetitive } \\
\text { Exploitation }\end{array}$} \\
\hline & \multicolumn{2}{|c|}{ Loading } & \multicolumn{2}{|c|}{ Loading } & \multicolumn{2}{|l|}{ Loading } & \multicolumn{2}{|l|}{ Loading } & \multicolumn{2}{|l|}{ Loading } \\
\hline & Factor 1 & $\begin{array}{l}\text { Comm } \\
\text { unality }\end{array}$ & Factor 1 & $\begin{array}{l}\text { Comm } \\
\text { unality }\end{array}$ & Factor 1 & $\begin{array}{l}\text { Comm } \\
\text { unality }\end{array}$ & Factor 1 & $\begin{array}{l}\text { Comm } \\
\text { unality }\end{array}$ & Factor 1 & $\begin{array}{l}\text { Comm } \\
\text { unality }\end{array}$ \\
\hline \multicolumn{11}{|l|}{$\begin{array}{l}\text { External Market Sources of } \\
\text { Information: }\end{array}$} \\
\hline Suppliers & 0.451 & 0.203 & & & & & & & & \\
\hline Customers & 0.543 & 0.295 & & & & & & & & \\
\hline Competitors & 0.599 & 0.359 & & & & & & & & \\
\hline Consultants & 0.675 & 0.456 & & & & & & & & \\
\hline \multicolumn{11}{|l|}{ External Institutional } \\
\hline \multicolumn{11}{|l|}{ Sources of Information: } \\
\hline Universities & 0.753 & 0.567 & & & & & & & & \\
\hline Research Institutes & 0.744 & 0.554 & & & & & & & & \\
\hline \multicolumn{11}{|l|}{$\begin{array}{l}\text { External Other Sources of } \\
\text { Information: }\end{array}$} \\
\hline Conferences & 0.784 & 0.615 & & & & & & & & \\
\hline Publications & 0.804 & 0.646 & & & & & & & & \\
\hline Professional Associations & 0.804 & 0.646 & & & & & & & & \\
\hline Internet & 0.620 & 0.384 & & & & & & & & \\
\hline IS as a Dpt. of the Firm & & & 0.729 & 0.531 & & & & & & \\
\hline R\&D as a Dpt. of the Firm & & & 0.763 & 0.582 & & & & & & \\
\hline Eng. as a Dpt. of the Firm & & & 0.752 & 0.565 & & & & & & \\
\hline $\begin{array}{l}\text { The Firm launched a new } \\
\text { product in } 2014\end{array}$ & & & & & 0.844 & 0.712 & & & & \\
\hline $\begin{array}{l}\text { The Firm launched a new } \\
\text { service in } 2014\end{array}$ & & & & & 0.844 & 0.712 & & & & \\
\hline \multicolumn{11}{|l|}{ Marketing Innovation in: } \\
\hline Packaging & & & & & & & 0.841 & 0.708 & & \\
\hline Advertising & & & & & & & 0.924 & 0.854 & & \\
\hline Distribution & & & & & & & 0.921 & 0.848 & & \\
\hline Pricing & & & & & & & 0.866 & 0.749 & & \\
\hline \multicolumn{11}{|l|}{ Process and Org. } \\
\hline Manufacturing & & & & & & & & & 0.741 & 0.550 \\
\hline Logistics & & & & & & & & & 0.820 & 0.673 \\
\hline Support & & & & & & & & & 0.840 & 0.706 \\
\hline Process Design & & & & & & & & & 0.918 & 0.843 \\
\hline Decision Making & & & & & & & & & 0.913 & 0.834 \\
\hline External Relations & & & & & & & & & 0.854 & 0.729 \\
\hline $\begin{array}{l}\text { Eigenvalue } \\
\% \text { of Total Variance }\end{array}$ & $\begin{array}{l}4.726 \\
90\end{array}$ & & $\begin{array}{l}1.678 \\
121\end{array}$ & & $\begin{array}{l}1.424 \\
113\end{array}$ & & $\begin{array}{l}1.678 \\
121\end{array}$ & & $\begin{array}{l}4.335 \\
96\end{array}$ & \\
\hline
\end{tabular}

legend: ${ }^{*} p<0.05 ;{ }^{* *} p<0.01 ;{ }^{* * *} p<0.001$ 
summarizes the resultant loadings for the relevant factor. Strategic absorptive capacity is represented by one underlying factor encompassing $90 \%$ of total variance.

Operational absorptive capacity is defined as the ability of the firm to reach outside its boundaries for operational knowledge (i.e., engineering, operational, information systems). Since an innovation survey is the source of the data utilized, no direct question is related to this type of knowledge. A proxy is used following Setia and Patel (2013), whereby they deviate from Cohen and Levinthal's (1990) operationalization of absorptive capacity as R\&D spending. The authors object to the use of this measurement because of its static nature, while they view absorptive capacity as a process or a capability, more suitable to represent operational management knowledge. They operationalize absorptive capacity as "the degree to which the OM department interacts with stakeholders inside and outside the organization to acquire new knowledge (p. 417)." Similarly, Patel and colleagues (2012) argue that operational absorptive capacity allows firms to rapidly analyze and act on changes to the operational environment, like changes in demand, and to quickly increase the range and mobility of machines, labor, and material. Finally, the authors state that operational absorptive capacity could influence the company's ability to achieve a competitive advantage through manufacturing flexibility. The proxy used in this study is the level of new support processes acquired by the firm. The assumption is that new support processes are an indication of how operational absorptive capacity influences incremental and repetitive exploitation. The operationalization of this variable is by assigning to $O A C A P$ the answers corresponding to the incorporation of new support processes included in the survey. The model depicted in Chapter 3 is used to verify the validity of this new definition. The new $O A C A P$ variable rendered a 
better fit in the regression (Standard Error of 0.026 vs. 0.036 ). Table 3.2 shows R2 for the original model vs. the model with the new definition of $O A C A P$. As shown, the new variable introduces significantly higher descriptive power than the original model (R2 of 0.35 vs. 0.71$)$.

\begin{tabular}{|c|c|c|}
\hline \multicolumn{2}{|l|}{$\begin{array}{l}\text { Table 3.2 Explanatory Power of Model with New Operational } \\
\text { Absorptive Capacity }\end{array}$} \\
\hline Equation & Essay I Model R2 & Essay II Model R2 \\
\hline EXPLORE & $0.1170 * * *$ & $0.1352 * * *$ \\
\hline IEXPLOITE & $0.1122 * \star *$ & $0.1352 * \star *$ \\
\hline REXPLOITE & $0.1253 * * *$ & $0.4429 * * *$ \\
\hline
\end{tabular}

\section{Dependent Variables}

The exploratory function of ambidexterity is covered by identifying whether the firm launched new products or services during 2014. According to the Chilean National Innovation Survey, product innovation is the introduction to the market of a new good or service, or a significantly improved good or service, regarding its characteristics or its use. Factor analysis is conducted on these two dichotomous variables. The same procedure as for strategic absorptive capacity and operational absorptive capacity is used to determine the relevant underlying factors. One factor proved significant (i.e., eigenvalue larger than 1.0) describing $113 \%$ of the variability, defined as exploration. 
Following Piao and Zajac (2016), exploitation is divided into two functions: incremental exploitation, representing incremental innovation or a new design for existing products that I assume is influenced positively by both strategic and operational absorptive capacity; and repetitive exploitation, which is the repetition of existing designs of existing products. Incremental exploitation is addressed in the survey by four questions regarding improved marketing practices ranging from new packaging to new pricing mechanisms. Factor analysis is conducted on these four dichotomous variables using the same methodology as before. One factor is found to be representative (i.e., eigenvalue greater than 1.0) explaining $104 \%$ of the variability and is defined as incremental exploitation.

Repetitive exploitation is represented by six questions covering improvements in manufacturing, logistics and operational support methods as well as the inclusion of decision making, external relations, and process design practices. Factor analysis is conducted on these six dichotomous variables using the same methodology as before. One factor is found to be representative (i.e., eigenvalue larger than 1.0) explaining $96 \%$ of the variability, defined as repetitive exploitation. Table 3.1 presents the factor analysis results of the dependent and independent variables.

\section{Moderating Variables}

Following Álvarez et al.’s (2015) recommendation, I operationalize companies' classification by industry sector by the dichotomous variable Sector, which takes the value of 0 for manufacturing and 1 for service firms. With this definition, I have a balanced sample of approximately 2,000 records in each area. 
To capture the cooperative nature of companies, I create the variable Cooperation to represent those companies that innovated in cooperation with other entities. "Cooperation" is defined as the firm's active participation with other companies or non-commercial institutions (e.g., universities, research institutions, others) in innovation activities. The question representing this variable in the survey is dichotomous with a value of 0 for no cooperation and a value of 1 for a firm engaged in cooperation. The intensity of cooperation is not captured by the questionnaire.

Finally, to represent the impact of the $R \& D+i$ incentive legislation on the relationship between strategic absorptive capacity and exploration, I create a dichotomous variable New Incentive Legislation that takes the value of 0 for years 2009 to 2012 and 1 from 2013 onwards. The new legislation was passed in 2012; I assume that, in general, it takes one year to perceive the effects of the legislation.

\section{Control Variables}

Potential confounding effects were controlled for by including various relevant sets of variables; these sets are different for each model, but all models do have at least 8 control variables. Because large companies may lack the flexibility to explore even though they might have more resources, company size was included as a variable. Company age was included as the logarithm of the number of years from its founding since previous studies have shown that aging companies are more likely to develop innovation that exploits existing competencies (Sørensen \& Stuart, 2000).

Diversity in organizational tenure could affect strategic organizational changes (Milliken \& Martins, 1996). Therefore, the logarithms of the number of workers in 
three distinct areas (i.e., engineering, information systems, and R\&D) are used as proxies of diversity.

Companies are likely to apply their existing in-depth knowledge to customer groups and geographic regions that are like those they already serve. The application of this in-depth knowledge could result in exploitative innovation (van Wijk et al., 2012). Therefore, there was control for geographic region; in the case of Chile, there are 15 geographic regions.

Additionally, increasing levels of education may relate positively to employee ambidexterity since the higher the education level, the greater the cognitive abilities for processing information and learning (Adler et al., 1999; Papadakis et al., 1998). Educational levels were controlled for by including a dummy variable reflecting employees with up to high school education. Employees with no education were the reference group.

Fixed effect method considers the variability of selected parameters over time within themselves. To avoid exogenous time effects (i.e., outside events occurring at a specific time within the analysis period), a time-control variable is implemented (i.e., Year).

Training is considered as an essential capability for the assimilation of knowledge, particularly in the international arena. Lane, Salk, \& Lyles (2001), in the context of an international joint venture, consider the provision of training, technology, and managerial assistance essential to assimilating local knowledge.

The analysis controls by age, since established companies have more access to external sources and introduce new products more frequently than young firms (Zahra 
\& Nielsen, 2002). Age is measured by the number of years since the company has been established.

Álvarez et al. (2015) concluded that being an exporter and using patent protection have a positive effect on the probability of engaging in innovation investment in manufacturing and service sectors. Exports as a percentage of total sales is used as a control variable in this study.

\section{Statistical Methods}

The purpose of this study is to understand the moderating effect of relevant variables in the relationship between absorptive capacity and ambidexterity. The availability of longitudinal data allows for the analysis of the influence over time of such variables. To explore the group effect as well as the time effect of the selected variables, fixed effects and random effects models are used. Even though both models are used initially, a Hausman test is performed to determine which method is more accurate given the nature of the data (Fitzmaurice, Laird, \& Ware, 2012). A multiple analysis of variance test is performed prior to the application of the fixed and random effects models to test whether the independent grouping variable simultaneously explains a statistically significant amount of variance in the dependent variables. The Wilk's Lambda U test, the Lawley-Hotelling test, the Pillai test, and Roy's Largest Root test are performed.

Factor analyses are conducted using the polychoric correlation matrix in all cases since the underlying variables were all dichotomous (Netter et al., 1990).

An OLS analysis is performed along with the fixed and random effects models to validate the assumption of lower estimated standard errors with higher test statistics 
due to the lack of independence of observation inherent to longitudinal data analysis (Fitzmaurice et al., 2012). Table 3.3 shows the results for H1 using OLS, fixed and random effects models. The results validate the assumption and, together with the results of the Hausman test, a fixed effects model is selected to examine the hypotheses (Table 3.4). For purposes of better clarity in the results, the independent variable strategic absorptive capacity is centered. Finally, I perform a multicollinearity test by using variance inflation factors (VIF). The highest value is 2.47 with an average of 2.34 for all variables, which is significantly below the cutoff threshold of 10 (Netter et al., 1990).

\begin{tabular}{|c|c|c|c|}
\hline Variable & ols & fe & re \\
\hline$S A C A P$ & $\begin{array}{c}.09132497 * * * \\
(.0198359)\end{array}$ & $\begin{array}{l}.05296515^{*} \\
(.0266534)\end{array}$ & $\begin{array}{c}.06848653 * * * \\
(.0189342)\end{array}$ \\
\hline Sector & $\begin{array}{c}-.03643764 \\
(.0319852)\end{array}$ & $\begin{array}{c}-.4483161^{\star * \star} \\
(.0809972)\end{array}$ & $\begin{array}{c}-.13813808 * \star \star \\
(.0375475)\end{array}$ \\
\hline $\begin{array}{l}\mathrm{F} \\
\text { chi2 }\end{array}$ & & $6.44 * \star \star$ & $91.49 * * *$ \\
\hline
\end{tabular}

\begin{tabular}{|l|cc|c|c|}
\hline \multicolumn{4}{|l|}{ Table 3.4 Hausman Test } \\
\hline & \multicolumn{2}{|c|}{ Coefficients } & & \\
& (b) & (B) & (b-B) & Sqrt(diag(V_b-V_B) \\
& Fixed & Random & Difference & S.E. \\
\hline SACAP & -.0050274 & .0882864 & -.0933138 & .0249559 \\
l.Sector & -.4322774 & -.0190384 & -.4132391 & .086492 \\
Sector\#c.SACAP & & & & \\
\multicolumn{1}{|l|}{1} & .0379328 & -.0373376 & .0752704 & .0292738 \\
\hline
\end{tabular}

$\mathrm{b}=$ consistent under Ho and Ha; obtained from xtreg

$\mathrm{B}=$ inconsistent under $\mathrm{Ha}$, efficient under Ho; obtained from xtreg

Test: Ho: difference in coefficients not systematic

$\operatorname{Chi2}(3)=(b-B)^{\prime}\left[\left(\mathrm{V} \_b-V \_B\right)^{\wedge}\{-1)\right](b-B)=36.85$

Prob $>$ chi $2=0.0000$ 


\section{Results}

\section{Main Results}

Hypothesis $1(\mathrm{H} 1)$ is used to compare the results from OLS, fixed and random methods. The fixed effects method provides better goodness of fit than the OLS method $(\mathrm{F}=6.44$, Prob. $>\mathrm{F}=0.000$ ). By the same token, $\mathrm{H} 0$ (i.e., time specific variance components are 0 ) is rejected for the random effect method, concluding that there is a significant random effect in the panel data and that the random effect method deals with heterogeneity better than the OLS method; results are shown in Table 3.3 (Park, 2011). A Hausman test is used to determine which effect, i.e., fixed or random, is more relevant and significant in the panel data (Park, 2011). Results from the test indicate that individual effects are significantly correlated with at least one regressor in the model; thus, the fixed effects method is preferable (Table 3.4). Therefore, the fixed effects method is used to validate all the hypotheses.

In all cases, the independent variable strategic absorptive capacity $S A C A P$ is centered over its mean to facilitate the interpretation of the results. All models including the moderating variable are compared against the same model without the moderating effect.

Table 3.5 shows the descriptive statistics for the DV and IVs, and Table 3.6 shows the results for the analysis of hypothesis 1 . The standardized coefficient for the interacting term is positive and significant at the .05 level. The result indicates that the impact of strategic absorptive capacity $(S A C A P)$ on exploration is stronger for service companies than those on the manufacturing sector, validating H1. Figure 3.2 shows 
that for service companies the larger the strategic absorptive capacity, the larger the effect on exploration.

\begin{tabular}{|c|c|c|c|c|c|c|c|}
\hline Variable & & Mean & Std. Dev. & Min & Max & \multicolumn{2}{|c|}{ Observations } \\
\hline EXPLORE & $\begin{array}{l}\text { overall } \\
\text { between } \\
\text { within }\end{array}$ & .1154691 & $\begin{array}{l}.2607094 \\
.1922673 \\
.177941\end{array}$ & $\begin{array}{c}0 \\
0 \\
- \\
.4993855\end{array}$ & $\begin{array}{l}.922282 \\
.922282 \\
.7303238\end{array}$ & $\begin{array}{c}\mathrm{N}= \\
\mathrm{n}= \\
\mathrm{T}-\mathrm{bar}=\end{array}$ & $\begin{array}{c}3762 \\
768 \\
4.89844\end{array}$ \\
\hline SACAP & $\begin{array}{l}\text { overall } \\
\text { between } \\
\text { within }\end{array}$ & 2.578385 & $\begin{array}{r}.8594461 \\
.7944508 \\
.3884195\end{array}$ & $\begin{array}{l}1.310892 \\
1.331444 \\
.8122066\end{array}$ & $\begin{array}{l}5.218919 \\
5.090522 \\
4.409134\end{array}$ & $\begin{array}{c}\mathrm{N}= \\
\mathrm{n}= \\
\mathrm{T}-\mathrm{bar}=\end{array}$ & $\begin{array}{c}723 \\
334 \\
2.16467\end{array}$ \\
\hline Sector & $\begin{array}{l}\text { overall } \\
\text { between } \\
\text { within }\end{array}$ & .5178097 & $\begin{array}{l}.4997491 \\
.4391853 \\
.2327064\end{array}$ & $\begin{array}{c}0 \\
0 \\
-.148857\end{array}$ & $\begin{array}{c}1 \\
1 \\
1.184476\end{array}$ & $\begin{array}{c}\mathrm{N}= \\
\mathrm{n}= \\
\mathrm{T}-\mathrm{bar}=\end{array}$ & $\begin{array}{c}3762 \\
768 \\
4.89844\end{array}$ \\
\hline
\end{tabular}




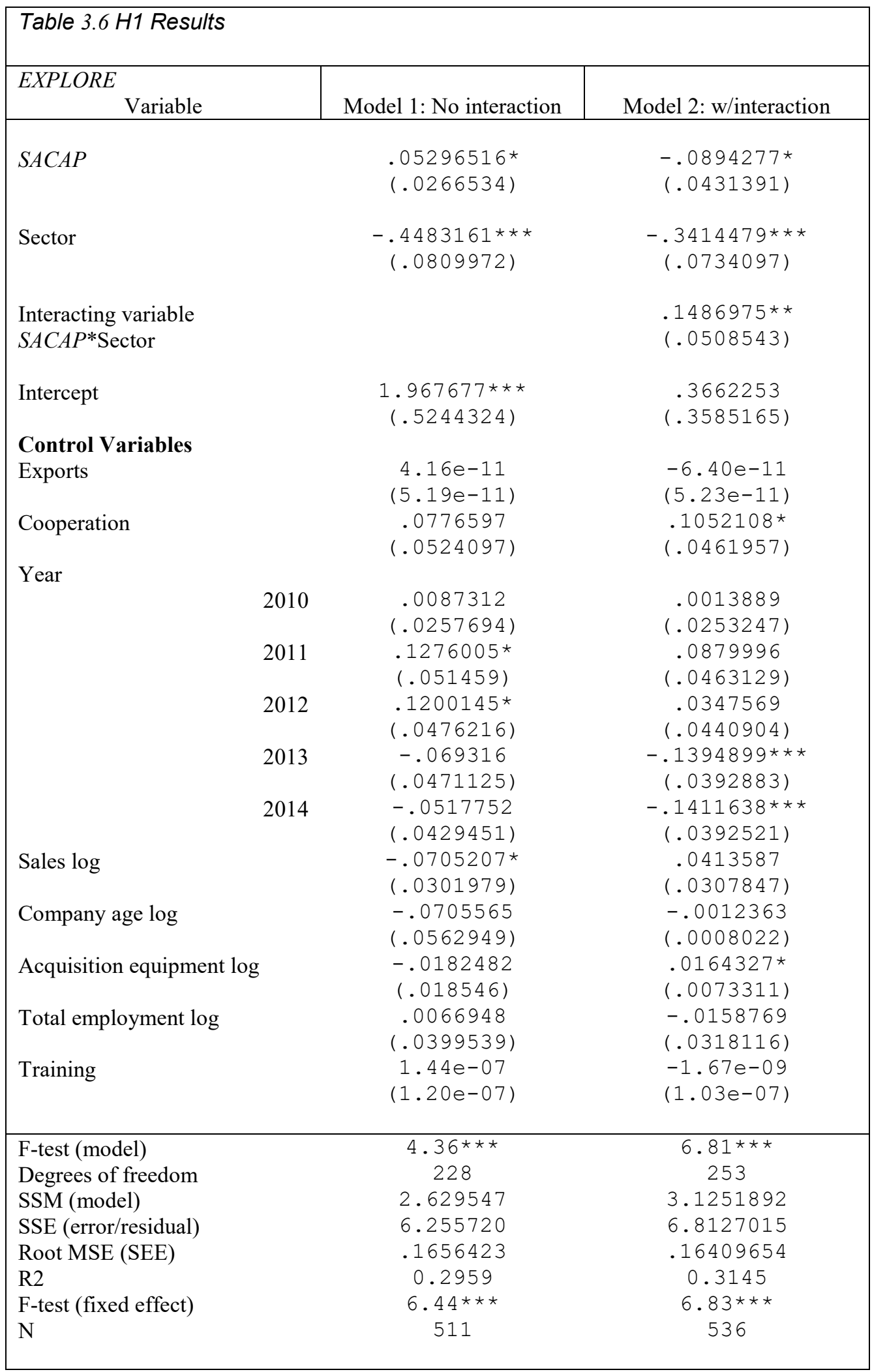

legend: ${ }^{*} \mathrm{p}<0.05 ; * * \mathrm{p}<0.01 ; * * * \mathrm{p}<0.001$ 


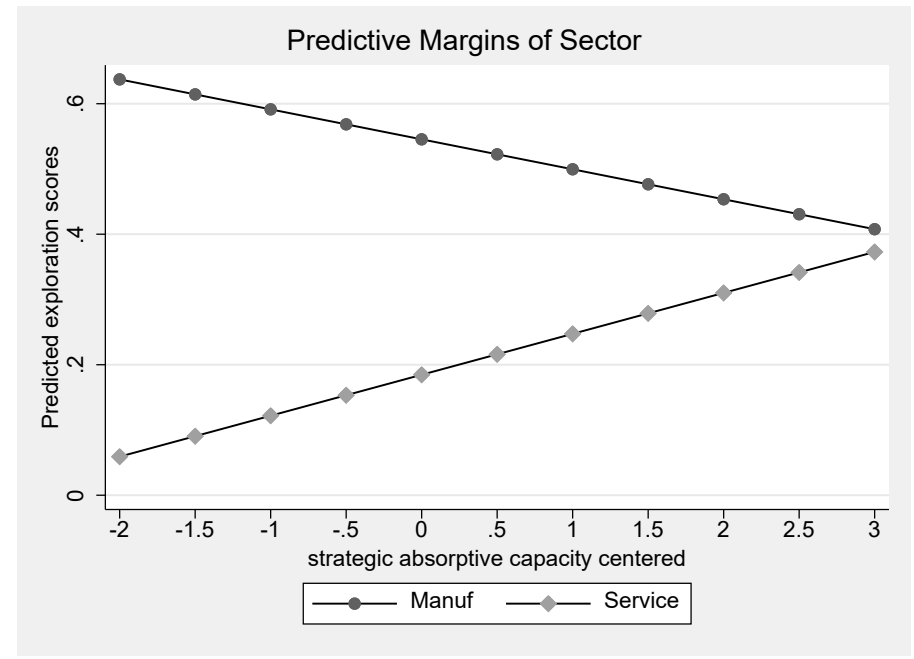

Figure 3.2 Interaction Effect for $\mathrm{H1}$

Similar behavior is observed in the effect of $S A C A P$ on incremental exploitation, validating H2 (Table 3.7). Figure 3.3 shows a behavior of SACAP like the interaction with exploration; the difference being that $S A C A P$ has a similar (though less intense) effect on the incremental exploitation of manufacturing firms.

Exploring the relationship between collaborating firms and the effect of SACAP on exploration, Model 5 (i.e., no interaction) shows that for the same level of strategic absorptive capacity, collaborating companies have a larger positive impact on exploration $(10.9 \%$ at the 0.05 level). When the interacting term is included into the model (Model 6), the effects of SACAP and the interacting term show that the effect of $S A C A P$ is smaller in magnitude for collaborating firms, validating $\mathrm{H} 3$ (Table 3.8). Figure 3.4 shows that the incremental effort on strategic absorptive capacity has diminishing returns, so a company with strategic absorptive capacity and engaged in collaboration should moderate the use of such capacity because the effect on exploration diminishes. These findings indicate that strategic absorptive capacity and collaboration might act as substitutes. 


\begin{tabular}{|c|c|c|}
\hline \multicolumn{3}{|l|}{ Table 3.7 H2 Results } \\
\hline $\begin{array}{r}\text { IEXPLOITE } \\
\text { Variable }\end{array}$ & Model 3: No interaction & Model 4: w/interaction \\
\hline$S A C A P$ & $\begin{array}{l}.2147144 * \star \star \\
(.0265863)\end{array}$ & $\begin{array}{l}.1362034 * \star \\
(.0518782)\end{array}$ \\
\hline Sector & $\begin{array}{c}-.1599189 \star \\
(.0778928)\end{array}$ & $\begin{array}{l}.0518782 \\
(.1046936)\end{array}$ \\
\hline $\begin{array}{l}\text { Interacting variable } \\
S A C A P^{*} \text { Sector }\end{array}$ & & $\begin{array}{l}.1270975 \star \\
(.0593852)\end{array}$ \\
\hline Intercept & $\begin{array}{l}.9505546 * \\
(.4203827)\end{array}$ & $\begin{array}{l}-.2720011 \\
(.3946622)\end{array}$ \\
\hline Control Variables & & \\
\hline Sales log & $\begin{array}{l}-.0259321 \\
(.0213438)\end{array}$ & $\begin{array}{l}.0563386 \star \star \\
(.0197338)\end{array}$ \\
\hline Company age log & $\begin{array}{c}-.036303 \\
(.0506796)\end{array}$ & $\begin{array}{l}-.0592255 \\
(.0526797)\end{array}$ \\
\hline Training & $\begin{array}{c}4.50 e-08 \\
(1.14 e-07)\end{array}$ & $\begin{array}{c}7.64 e-08 \\
(1.16 e-07)\end{array}$ \\
\hline Total exp. innov act. log & $\begin{array}{l}.0713036 * \star \star \\
(.0204101)\end{array}$ & $\begin{array}{l}-.0160222 \\
(.0103776)\end{array}$ \\
\hline F-test (model) & $10.38 * \star \star$ & $8.32 * \star \star$ \\
\hline Degrees of freedom & 233 & 236 \\
\hline SSM (model) & 4.9363856 & 3.6389261 \\
\hline SSE (error/residual) & 6.5178059 & 7.9422703 \\
\hline Root MSE (SEE) & .16725255 & .18344942 \\
\hline $\mathrm{R} 2$ & 0.4310 & 0.3142 \\
\hline F-test (fixed effect) & $5.75 * \star \star$ & $4.19 * \star \star$ \\
\hline $\mathrm{N}$ & 511 & 492 \\
\hline
\end{tabular}

legend: $* \mathrm{p}<0.05 ; * * \mathrm{p}<0.01 ; * * * \mathrm{p}<0.001$

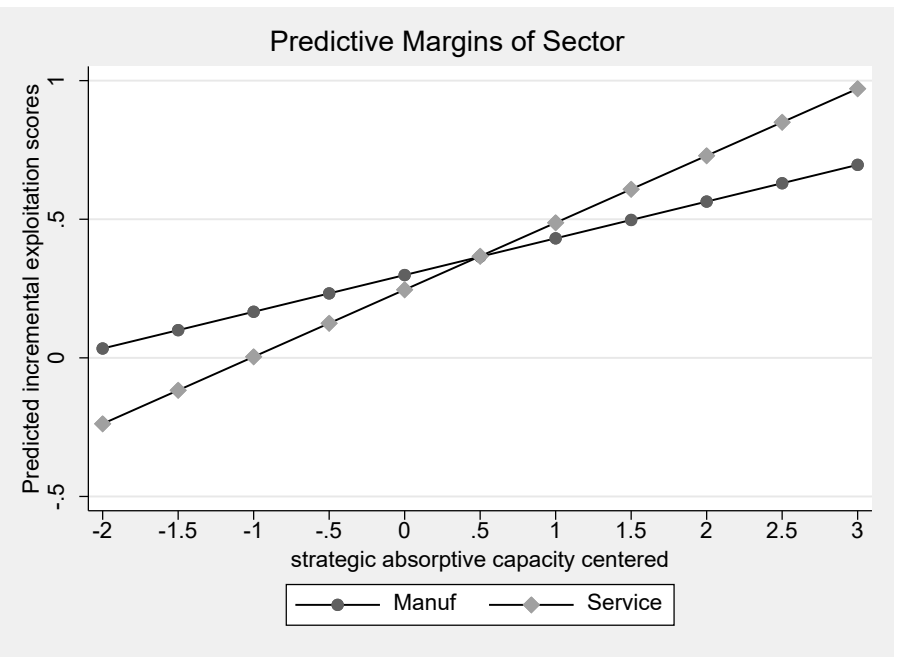

Figure 3.3 Interaction Effect for $\mathrm{H} 2$ 


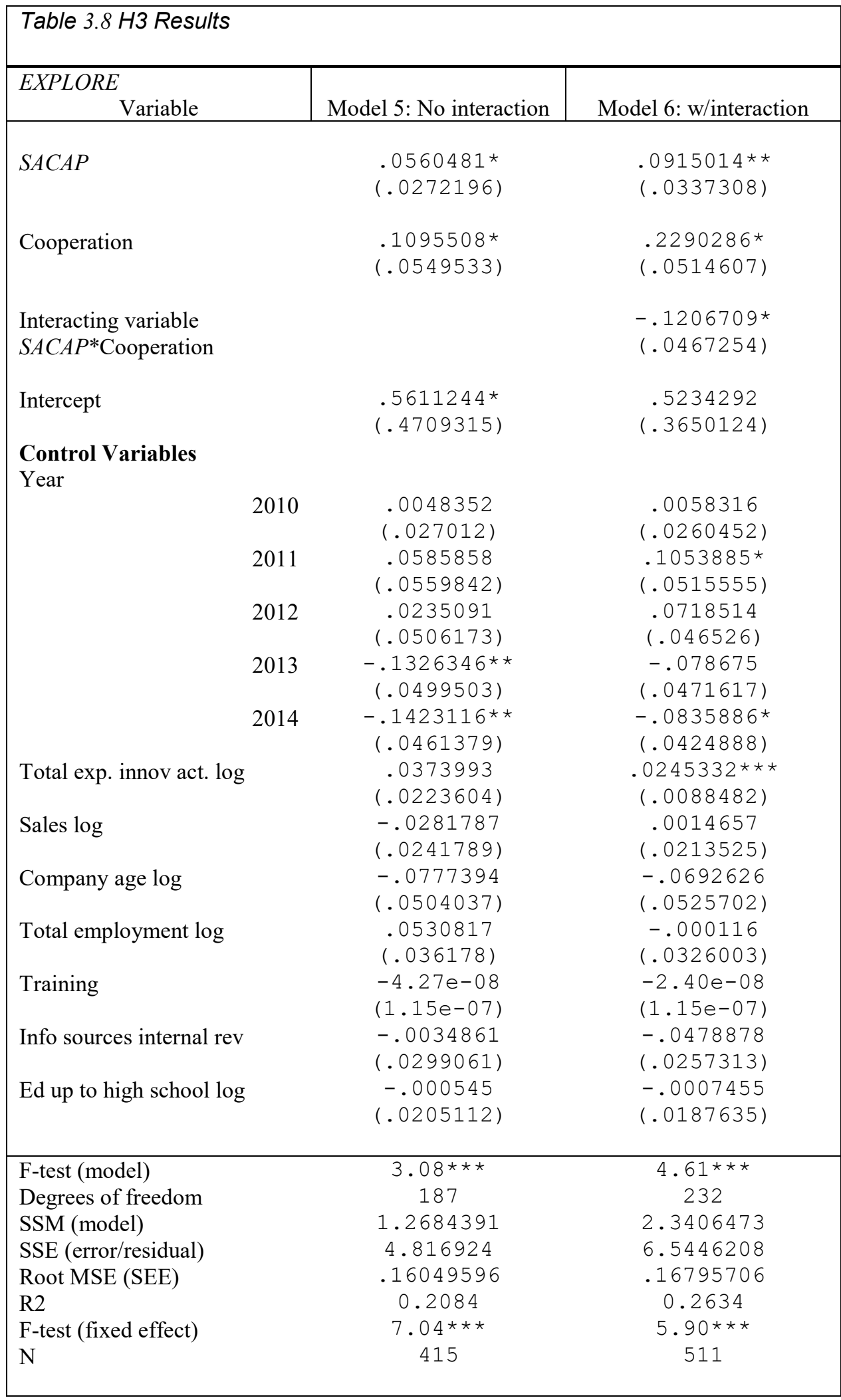

legend: ${ }^{*} \mathrm{p}<0.05 ; * * \mathrm{p}<0.01 ; * * * \mathrm{p}<0.001$ 


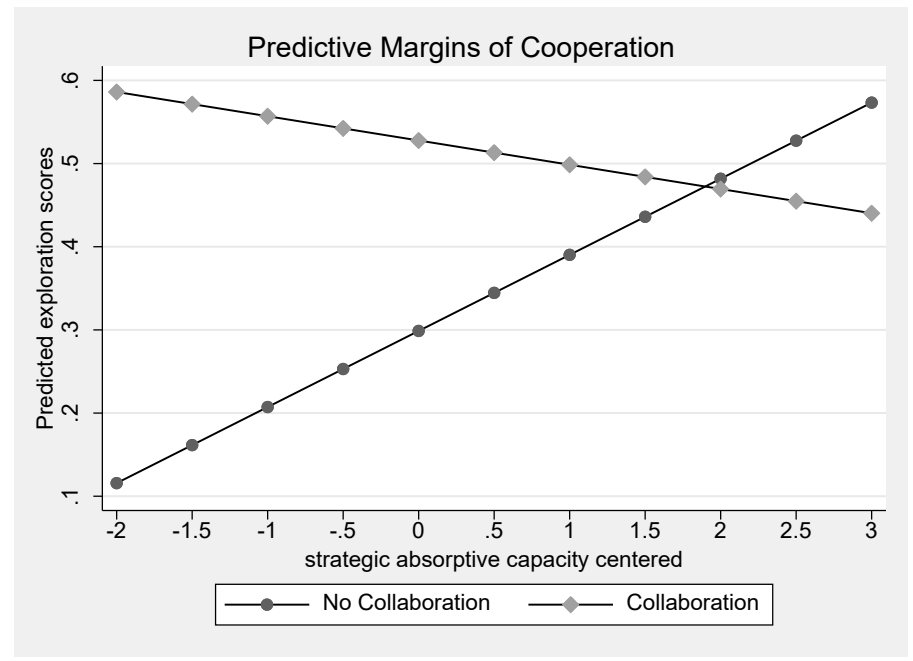

Figure 3.4 Interaction Effect for H3

H4 postulates a positive and strong effect of $S A C A P$ on incremental exploitation (Table 3.9). Here, the positive sign of the interactive term validates $\mathrm{H} 4$. Figure 3.5 shows that for increasing absorptive capacity efforts, collaborating firms achieve better incremental exploitation results; thus, companies that collaborate should increase their absorptive capacity efforts to achieve superior exploitation results. In summary, relative to independent firms, collaborative firms explore less and exploit more.

Operationalization of $\mathrm{H} 5$ is achieved through a dichotomous variable $\mathrm{New}$ Incentive Legislation. My results, though significant, contradict H5 (Table 3.10). Original innovation-incentive legislation was passed in Chile in 2009. The mechanism required collaboration with an external research institution, either a university or other institution duly accredited by the Innovation Agency. The effect of the legislation was not significant since, according to some reports, the process was cumbersome, and relationships between industry and academia were almost nonexistent. Due to this lack of success, the legislation was modified in 2012 to incentivize innovation within the firm, without the previous requirement. This modification brought a significant 


\begin{tabular}{|c|c|c|}
\hline \multicolumn{3}{|l|}{ Table 3.9 H4 Results } \\
\hline $\begin{array}{r}\text { IEXPLOITE } \\
\text { Variable }\end{array}$ & Model 7: No interaction & Model 8: w/interaction \\
\hline$S A C A P$ & $\begin{array}{l}.1428609 * * * \\
(.0215249)\end{array}$ & $\begin{array}{l}.0996177^{\star} \\
(.0401905)\end{array}$ \\
\hline Cooperation & $\begin{array}{l}.0841018 * \\
(.0381297)\end{array}$ & $\begin{array}{c}-.171014 * \star \\
(.0585047)\end{array}$ \\
\hline $\begin{array}{l}\text { Interacting variable } \\
S A C A P^{*} \text { Cooperation }\end{array}$ & & $\begin{array}{l}.1235755^{\star} \\
(.0520008)\end{array}$ \\
\hline Intercept & $\begin{array}{l}.0766422 \\
(.4096241)\end{array}$ & $\begin{array}{l}.1720486 \\
(.9005515)\end{array}$ \\
\hline Control Variables & & \\
\hline Total exp. innov act. $\log$ & $\begin{array}{c}.0883288 * \star * \\
(.022011)\end{array}$ & $\begin{array}{l}.0245332 * \star * \\
(.0088482)\end{array}$ \\
\hline Sales $\log$ & $\begin{array}{l}-.0024731 \\
(.0208712)\end{array}$ & $\begin{array}{l}.0014657 \\
(.0213525)\end{array}$ \\
\hline Company age log & $\begin{array}{l}-.0883272 \\
(.0452078)\end{array}$ & $\begin{array}{l}-.0692626 \\
(.0525702)\end{array}$ \\
\hline Total employment log & $\begin{array}{l}.0748082^{\star} \\
(.0313257)\end{array}$ & $\begin{array}{l}-.000116 \\
(.0326003)\end{array}$ \\
\hline Info sources internal rev & $\begin{array}{l}.0493014 * \\
(.0210413)\end{array}$ & $\begin{array}{l}-.0478878 \\
(.0257313)\end{array}$ \\
\hline Ed up to high school log & $\begin{array}{l}-.0082485 \\
(.0131175)\end{array}$ & $\begin{array}{l}-.0007455 \\
(.0187635)\end{array}$ \\
\hline Acquisition equipment $\log$ & $\begin{array}{r}-.0895629 * \star \star \\
(.0202538)\end{array}$ & $\begin{array}{r}-.0110192 \\
(.019784)\end{array}$ \\
\hline Obstacle lack of funds & $\begin{array}{l}-.0324682 \\
(.0195477)\end{array}$ & $\begin{array}{c}-.1362312 \star * \star \\
(.0391264)\end{array}$ \\
\hline F-test (model) & $13.04 * \star \star$ & $13.02 * \star \star$ \\
\hline Degrees of freedom & 279 & 140 \\
\hline SSM (model) & 4.2206951 & 2.9386389 \\
\hline SSE (error/residual) & 9.0326931 & 1.373939 \\
\hline Root MSE (SEE) & .17993122 & .09906488 \\
\hline $\mathrm{R} 2$ & 0.3185 & 0.6814 \\
\hline F-test (fixed effect) & $5.54 * \star \star$ & $13.75 * * \star$ \\
\hline $\mathrm{N}$ & 549 & 357 \\
\hline
\end{tabular}

legend: ${ }^{*} \mathrm{p}<0.05 ; * * \mathrm{p}<0.01 ; * * * \mathrm{p}<0.001$ 


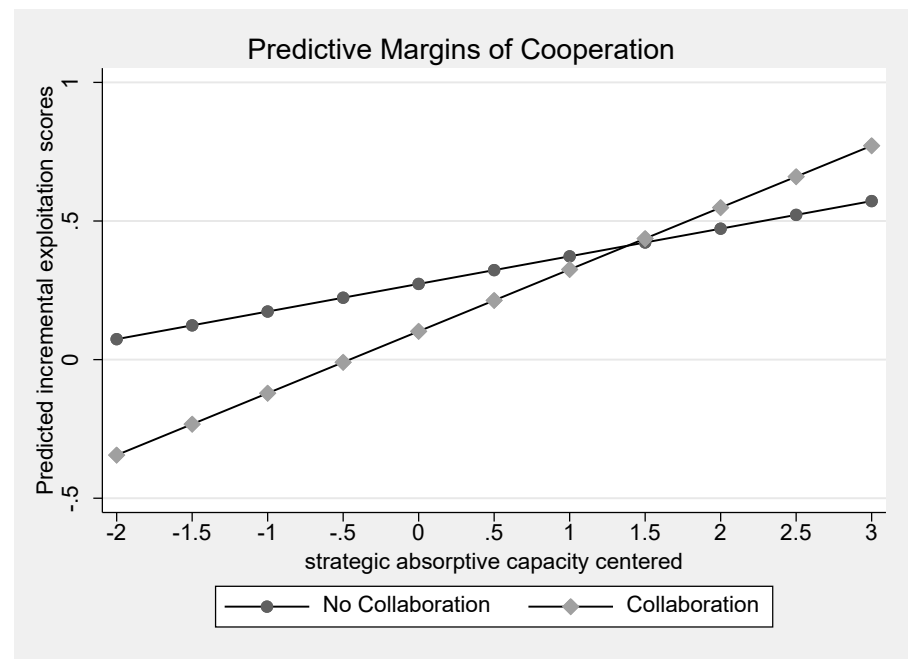

Figure 3.5 Interaction Effect for H4

increase in the application for tax incentives, as shown in Figure 3.6. However, this increase completely disincentivized reaching outside the firm to look for innovation sources. Therefore, the negative results observed validates the actual behavior of Chilean firms, i.e., the relationship between SACAP and EXPLORE is weaker due to the new incentive legislation, since Chilean firms did not use absorptive capacities for their exploratory efforts. This behavior is corroborated in Figure 3.7, where the existence of new legislation disincentivizes high levels of strategic absorptive capacities.

Similar behavior is observed between strategic absorptive capacity and incremental innovation, moderated by the new legislation (Table 3.11). Interestingly, Figure 3.8 shows that the incentive legislation has influenced using absorptive capacity to achieve higher levels of incremental exploitation. 


\begin{tabular}{|c|c|c|c|}
\hline \multicolumn{4}{|l|}{ Table 3.10 H5 Results } \\
\hline \multicolumn{2}{|l|}{ Variable } & Model 9: No interaction & Model 10: w/interaction \\
\hline \multicolumn{2}{|l|}{$S A C A P$} & $\begin{array}{l}.0497873 \\
(.0279318)\end{array}$ & $\begin{array}{l}.0699247 \star \\
(.0293669)\end{array}$ \\
\hline \multicolumn{2}{|l|}{ New Incentive Legislation } & $\begin{array}{l}-.0909404^{\star} \\
(.0412566)\end{array}$ & $\begin{array}{l}-.106102 * \star \\
(.0360677)\end{array}$ \\
\hline \multirow{2}{*}{\multicolumn{2}{|c|}{$\begin{array}{l}\text { Interacting variable } \\
S A C A P^{*} \text { New Incentive Leg. }\end{array}$}} & & $-.1475378 * * *$ \\
\hline & & & $(.0448132)$ \\
\hline \multicolumn{2}{|l|}{ Intercept } & $\begin{array}{l}1.020378 * \\
(.4808205)\end{array}$ & $\begin{array}{l}.8921889 * \\
(.3716907)\end{array}$ \\
\hline \multicolumn{4}{|l|}{$\begin{array}{l}\text { Control Variables } \\
\text { Year }\end{array}$} \\
\hline & 2010 & $\begin{array}{l}.0069009 \\
(.0244822)\end{array}$ & $\begin{array}{l}.0058316 \\
(.0260452)\end{array}$ \\
\hline & 2011 & $\begin{array}{l}.132342 \star \\
(.0513139)\end{array}$ & $\begin{array}{l}.1053885^{\star} \\
(.0515555)\end{array}$ \\
\hline & 2012 & $\begin{array}{l}.1143278^{*} \\
(.0465592)\end{array}$ & $\begin{array}{l}.0718514 \\
(.046526)\end{array}$ \\
\hline & 2013 & $\begin{array}{l}-.0079234 \\
(.0317702)\end{array}$ & $\begin{array}{l}-.078675 \\
(.0471617)\end{array}$ \\
\hline & 2014 & omitted & $\begin{array}{l}-.0835886 * \\
(.0424888)\end{array}$ \\
\hline \multicolumn{2}{|l|}{ Total exp. innov act. log } & $\begin{array}{l}.0573976 * \star \\
(.0205993)\end{array}$ & $\begin{array}{l}.047139 * \\
(.0211566)\end{array}$ \\
\hline \multicolumn{2}{|l|}{ Sales log } & $\begin{array}{l}-.0161052 \\
(.0225782)\end{array}$ & $\begin{array}{l}-.0189266 \\
(.0207228)\end{array}$ \\
\hline \multicolumn{2}{|l|}{ Company age log } & $\begin{array}{l}-.1358469 \star \\
(.0541031)\end{array}$ & $\begin{array}{l}-.1162484^{\star} \\
(.0558504)\end{array}$ \\
\hline \multicolumn{2}{|l|}{ Total employment log } & $\begin{array}{l}.0487231 \\
(.034017)\end{array}$ & $\begin{array}{l}-.0024736 \\
(.0345619)\end{array}$ \\
\hline \multicolumn{2}{|l|}{ Training } & $\begin{array}{l}-3.56 e-08 \\
(1.18 e-07)\end{array}$ & $\begin{array}{c}7.29 e-08 \\
(1.18 e-07)\end{array}$ \\
\hline \multicolumn{2}{|l|}{ Info sources internal rev } & $\begin{aligned}- & .0775864 * \star \star \\
& (.0263158)\end{aligned}$ & $\begin{array}{l}.0092586 \\
(.027525)\end{array}$ \\
\hline \multicolumn{2}{|l|}{ Ed up to high school log } & $\begin{array}{l}-.0226623 \\
(.0184355)\end{array}$ & $\begin{array}{l}-.0128942 \\
(.0154968)\end{array}$ \\
\hline \multicolumn{2}{|l|}{ Acquisition equipment log } & $\begin{array}{l}-.035713 \\
(.0185154) \\
\end{array}$ & $\begin{array}{l}-.0305099 \\
(.0189811)\end{array}$ \\
\hline F-test (model) & & $5.41 * \star \star$ & $3.45 * \star \star$ \\
\hline Degrees of freedom & & 225 & 238 \\
\hline SSM (model) & & 3.3341434 & 1.3180594 \\
\hline SSE (error/residual) & & 5.5511248 & 7.5672088 \\
\hline Root MSE (SEE) & & .15707217 & .17831151 \\
\hline R2 & & 0.3752 & 0.1483 \\
\hline F-test (fixed effect) & & $6.83 * * *$ & $5.72 * \star \star$ \\
\hline $\mathrm{N}$ & & 511 & 511 \\
\hline
\end{tabular}

legend: ${ }^{*} \mathrm{p}<0.05 ; * * \mathrm{p}<0.01 ; * * * \mathrm{p}<0.001$ 


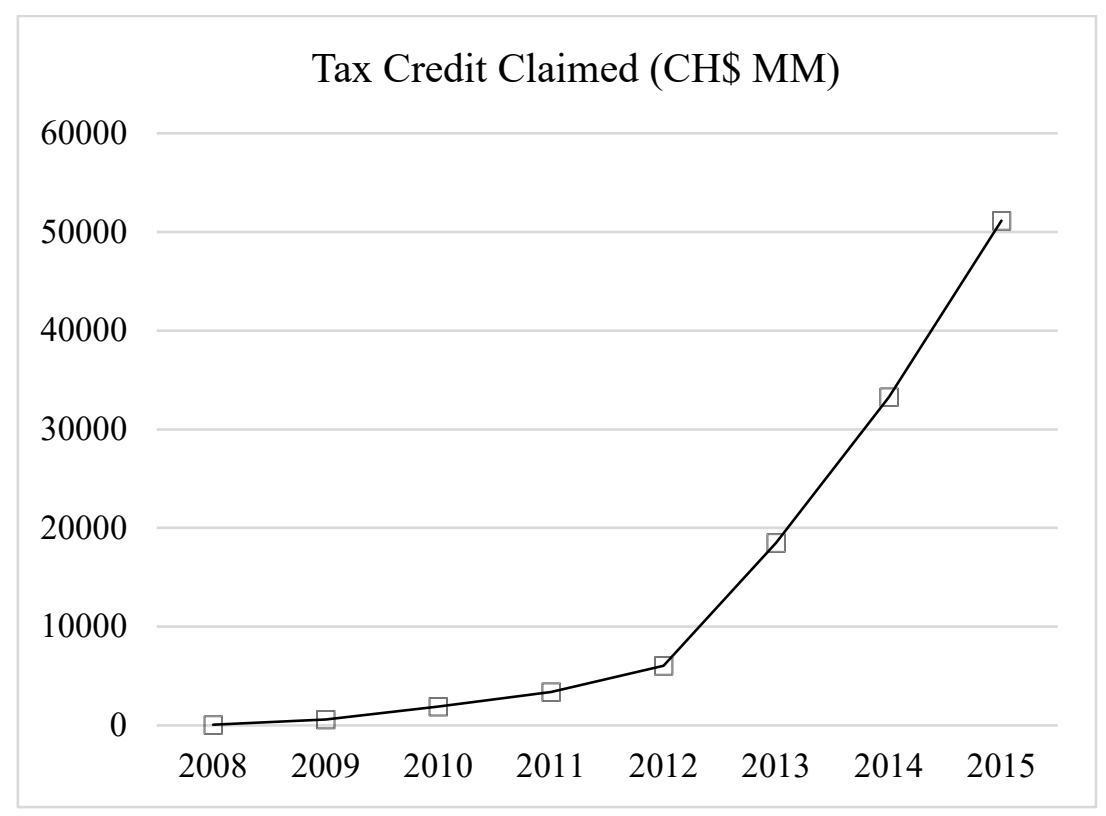

Figure 3.6 Chile's Innovation Incentive Legislation, Tax Credits Claims

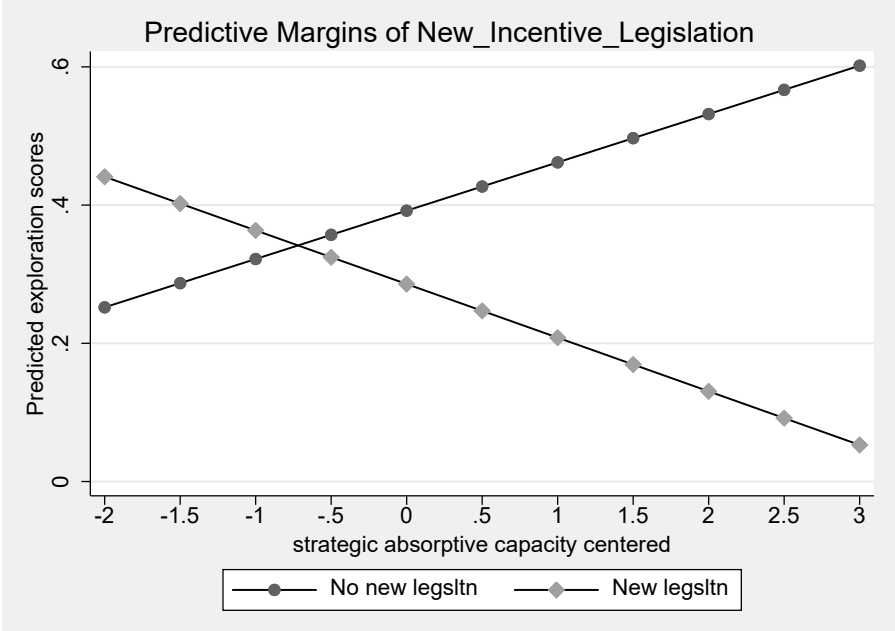

Figure 3.7 Interaction Effect for H5 


\begin{tabular}{|c|c|c|}
\hline $\begin{array}{r}\text { IEXPLOITE } \\
\text { Variable }\end{array}$ & Model 11: No interaction & Model 12: w/interaction \\
\hline$S A C A P$ & $\begin{array}{l}.2318464 * \star \star \\
(.026553)\end{array}$ & $\begin{array}{l}.2554509 * \star \star \\
(.0283556)\end{array}$ \\
\hline New Incentive Legislation & $\begin{array}{l}-.072353 \star \\
(.0348946)\end{array}$ & $\begin{array}{l}-.0635472 \\
(.0348257)\end{array}$ \\
\hline $\begin{array}{l}\text { Interacting variable } \\
S A C A P^{*} \text { New Incentive Leg. }\end{array}$ & & $\begin{array}{c}-.0970825 * \\
\quad(.04327)\end{array}$ \\
\hline Intercept & $\begin{array}{l}.1716179 \\
(.3542724)\end{array}$ & $\begin{array}{l}.3361439 \\
(.3588913)\end{array}$ \\
\hline Control Variables & & \\
\hline Total exp. innov act. log & $\begin{array}{l}.0736374 \star \star \star \\
(.020549)\end{array}$ & $\begin{array}{l}.0768471 \star \star \star \\
(.0204281)\end{array}$ \\
\hline Sales log & $\begin{array}{l}.0114624 \\
(.0200581)\end{array}$ & $\begin{array}{l}.0065878 \\
(.0200092)\end{array}$ \\
\hline Company age log & $\begin{array}{l}-.0200854 * \\
(.0519182)\end{array}$ & $\begin{array}{l}-.0560803 \\
(.0539271)\end{array}$ \\
\hline Total employment log & $\begin{array}{l}.0360215 \\
(.0335658)\end{array}$ & $\begin{array}{l}.0306618 \\
(.0333717)\end{array}$ \\
\hline Training & $\begin{array}{c}8.48 e-08 \\
(1.15 e-07)\end{array}$ & $\begin{array}{c}6.87 e-08 \\
(1.14 e-07)\end{array}$ \\
\hline Info sources internal rev & $\begin{array}{l}.0356556 \\
(.0261114)\end{array}$ & $\begin{array}{l}.04909 \\
(.0265771)\end{array}$ \\
\hline Ed up to high school log & $\begin{array}{l}-.0164595 \\
(.0150339)\end{array}$ & $\begin{array}{l}-.0135955 \\
(.0149632)\end{array}$ \\
\hline Acquisition equipment log & $\begin{array}{c}-.0931525 * * * \\
(.01839)\end{array}$ & $\begin{aligned} &-.0972383 * * \star \\
&(.0183274)\end{aligned}$ \\
\hline F-test (model) & $12.82 * \star \star$ & 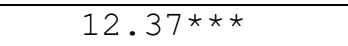 \\
\hline Degrees of freedom & 239 & 238 \\
\hline SSM (model) & 4.2499524 & 4.399173 \\
\hline SSE (error/residual) & 7.204239 & 7.0550184 \\
\hline Root MSE (SEE) & .17361814 & .17217124 \\
\hline $\mathrm{R} 2$ & 0.3710 & 0.3841 \\
\hline F-test (fixed effect) & $5.53 * \star \star$ & $5.62 * \star \star$ \\
\hline $\mathrm{N}$ & 511 & 511 \\
\hline
\end{tabular}

legend: $* \mathrm{p}<0.05 ; * * \mathrm{p}<0.01 ; * * * \mathrm{p}<0.001$ 


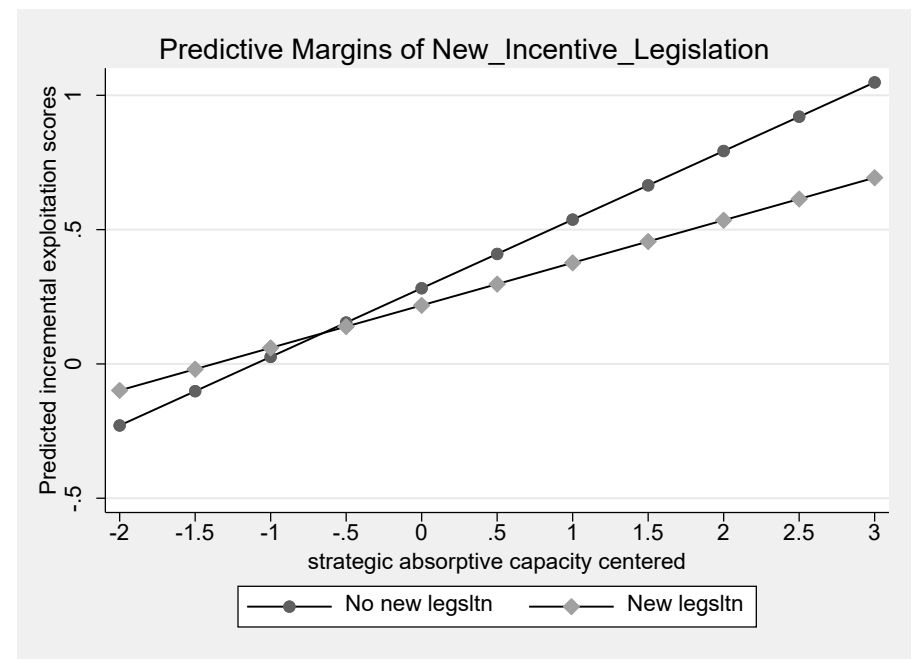

Figure 3.8 Interaction Effect for H6

\section{Other Results}

One of the original motivations of the research question is to establish not only the impact of strategic and operational absorptive capacity, on the ambidexterity capacity of a firm, but also to determine if there is any effect on performing both absorptive capabilities in a coordinated way. This assumption was tested in the original model, but the data set was not adequate to render meaningful results. This assumption is explored using the panel data set available for this study.

The analysis indicates that for a firm with average $S A C A P$, simultaneous engagement with operational absorptive capacity increases the exploratory ability of the firm (Table 3.12). The effect is very significant for high levels of $S A C A P$; if a firm has double the level of $S A C A P$ than the average, incorporating $O A C A P$ multiplies by 1.5 times the effect on exploration, as seen in Figure 3.9. The same effect is observed for incremental exploration, but with a lesser intensity (Table 3.13 and Figure 3.10). 
The interaction of both variables indicates a potential complementary effect between $S A C A P$ and $O A C A P$.

\section{Robustness Tests}

Several robustness checks are conducted to validate the model. At least eight sets of control variables as described above were introduced to each model to avoid a confounding effect. To evaluate heteroscedasticity and multicollinearity on the model, I run the analysis with robust standard errors, and VIFs are calculated for each model. In all cases, the influence of the variables was significant at the $1 \%$ level, and all VIFs were lower than 3.0, well below the rule-of-thumb cutoff of 10 (Netter et al., 1990).

In a meta-analysis on organizational ambidexterity and performance, Junni et al. (2013) discuss the different approaches taken by researchers measuring OA. When exploration and exploitation are combined, ambidexterity has been represented as the addition or multiplication of exploration and exploitation. For purposes of this study's robustness check, a single dependent variable representing ambidexterity was used, replacing EXPLORE, IEXPLOITE, and REXPLOITE. Since extant research has not addressed the separation between incremental and repetitive exploitation, a combination of EXPLORE is assumed as adding or multiplying a single variable, EXPLOITE, defined as the multiplication of IEXPLOITE and REXPLOITE. In both instances, representing the combination as an addition or multiplication, the explanatory power of analyzing the three separate variables is higher than the single variable, i.e., $R^{2}$ of 0.113 vs. 0.385 for the product, and $R^{2}$ of 0.183 vs. 0.385 for the sum. Finally, additional control variables are included representing doctoral and technical education levels, resulting in no significant changes to the results. 
Table 3.12 SACAP and OACAP Interaction for EXPLORE

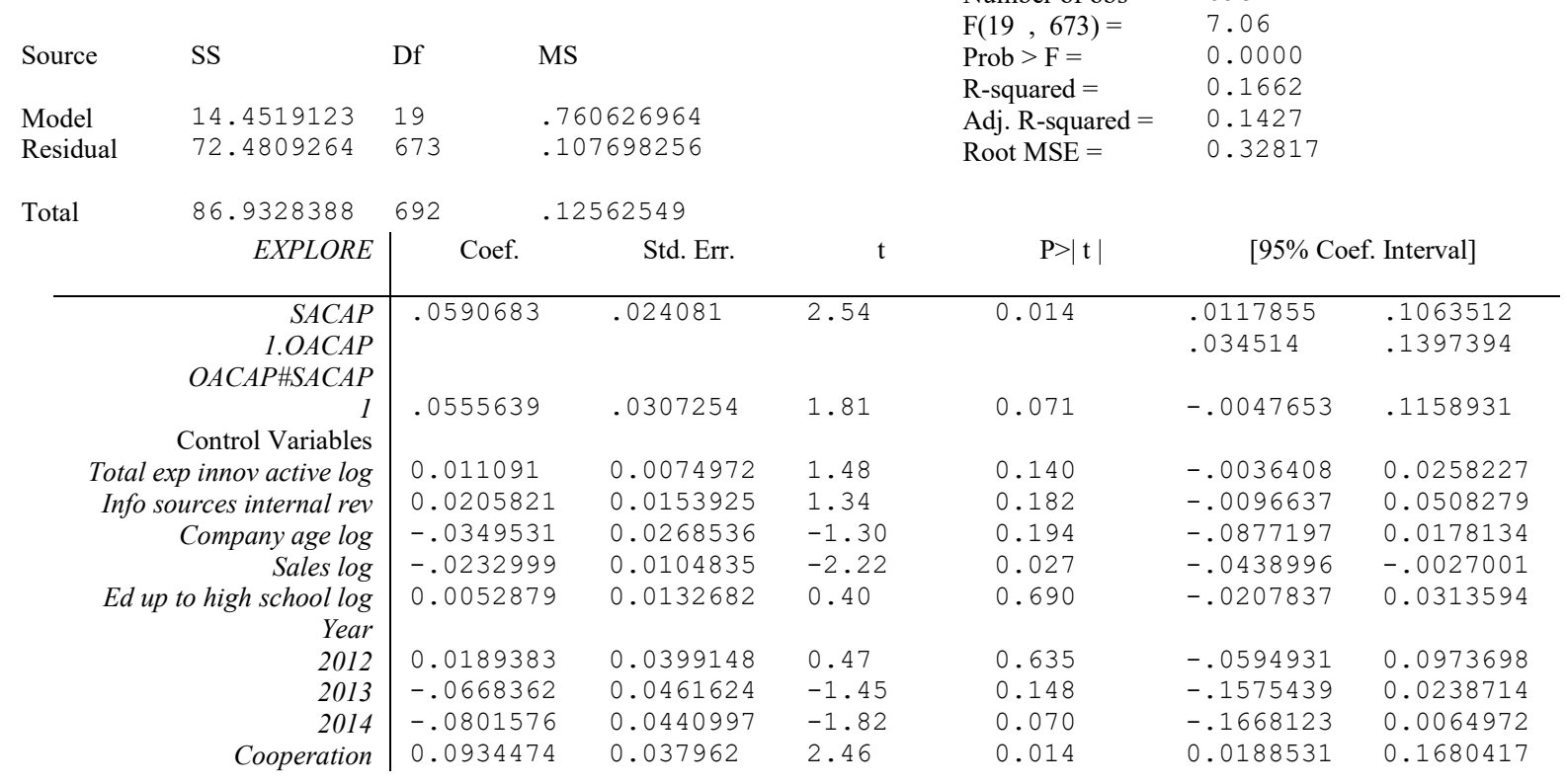

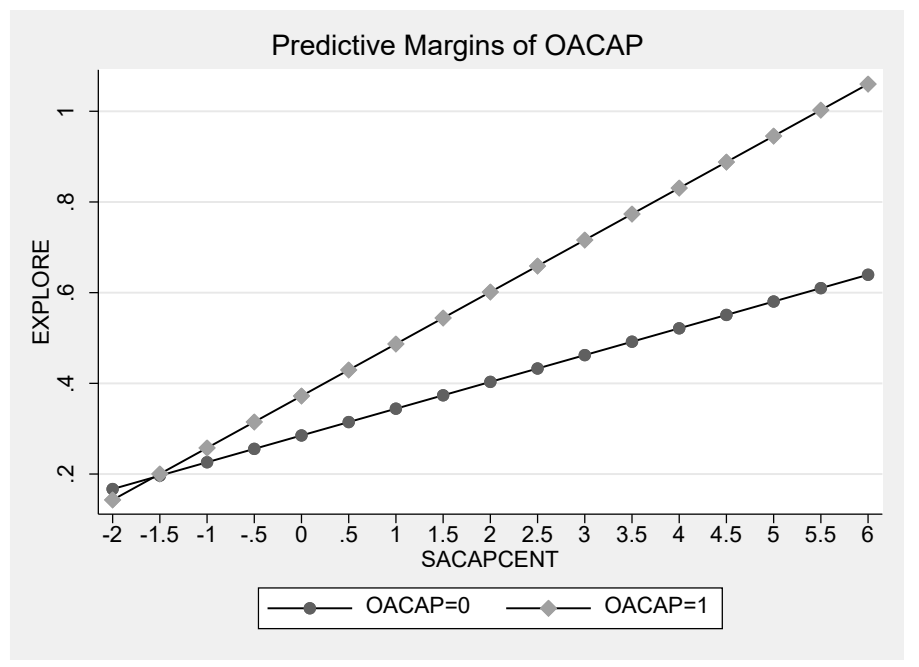

Figure 3.9 SACAP and OACAP Interaction for EXPLORE 
Table 3.13 SACAP and OACAP Interaction for IEXPLOITE

Random-effects GLS regression

Group variable: ID_Company

R-sq:

within $=0.2655$

between $=0.2329$

overall $=0.2169$

corr(u_i, X) $=0$ (assumed) $\begin{array}{ll}\text { Number of obs }= & 720 \\ \text { Number of groups }= & 334\end{array}$

Obs per group

$\min =\quad 1$

$\begin{array}{ll}\text { avg }= & 2.2\end{array}$

$\max =\quad 6$

Wald chi2(14) $=\quad$.

Prob $>$ chi $2=$

\begin{tabular}{|c|c|c|c|c|c|c|}
\hline IEXPLOITE & Coef. & Std. Err. & $\mathrm{t}$ & $\mathrm{P}>|\mathrm{t}|$ & \multicolumn{2}{|c|}{ [95\% Coef. Interval] } \\
\hline $\begin{array}{r}\text { SACAP } \\
\text { 1.OACAP }\end{array}$ & .0923279 & .0199878 & 4.62 & 0.000 & $\begin{array}{l}.0531526 \\
.082667\end{array}$ & $\begin{array}{l}.1315033 \\
.1768791\end{array}$ \\
\hline$O A C A P \# S A C A P$ & & & & & & \\
\hline $\begin{array}{r}1 \\
\text { Control Variables }\end{array}$ & .047043 & .0263225 & 1.79 & 0.074 & -.0045482 & .0986342 \\
\hline Total exp innov active log & -.0028679 & 0.0074195 & -0.39 & 0.699 & -0.017447 & 0.0117113 \\
\hline Info sources internal rev & -.0061413 & 0.0152331 & -0.40 & 0.687 & -.0360738 & 0.0237912 \\
\hline Company age log & -.0128117 & 0.0265755 & -0.48 & 0.630 & -.0650317 & 0.0394083 \\
\hline Sales log & 0.0012927 & 0.0103749 & 0.12 & 0.901 & -.0190937 & 0.0216791 \\
\hline $\begin{array}{r}\text { Ed up to high school log } \\
\text { Year }\end{array}$ & 0.0053433 & 0.0131307 & 0.41 & 0.684 & -.0204582 & 0.0311449 \\
\hline 2012 & 0.0069333 & 0.0395014 & 0.18 & 0.861 & -.0706858 & 0.0845524 \\
\hline 2013 & -.1006663 & 0.0456842 & -2.20 & 0.028 & -.1904345 & -.0108981 \\
\hline 2014 & -.0993659 & 0.043643 & -2.28 & 0.023 & -.1851231 & -.0136087 \\
\hline Cooperation & -0.051538 & 0.0375689 & -1.37 & 0.171 & -.1253598 & 0.0222837 \\
\hline
\end{tabular}

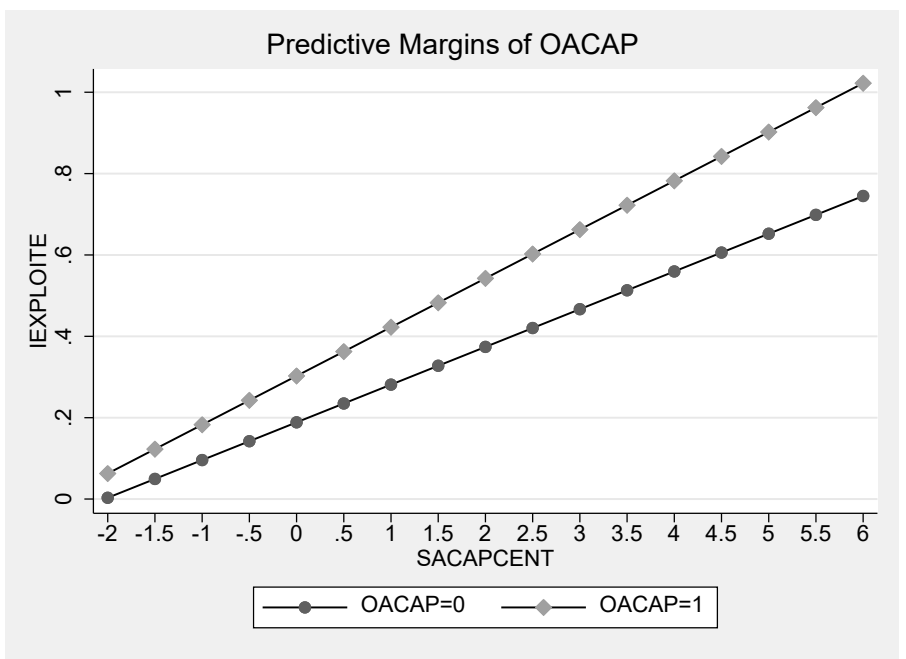

Figure 3.10 SACAP and OACAP Interaction for IEXPLOITE 


\section{Discussion and Conclusions}

Absorptive capacity and ambidexterity have been extensively studied separately as key capabilities for value generation and sustainability of competitive advantages (Cohen and Levinthal, 1990; O’Reilly and Tushman, 2008). However, limited research has been conducted in the interaction between these two constructs. This relationship is explored in Chapter 2 of this dissertation, contributing to the theoretical understanding of both constructs by introducing two types of absorptive capacities (i.e., strategic and operational absorptive capacities), and classifying ambidexterity as exploration, incremental exploitation, and repetitive exploitation, following Patel et al. (2012). The panel data analysis conducted in Chapter 3 allows for a more accurate representation of the interacting phenomena between these two constructs by refining the variable representing exploration, and moreover, replacing the operational absorptive capacity variable with a better proxy (i.e., support processes). This model refinement allows for the exploration of the interaction between the strategic and operational absorptive capacity constructs. The analysis indicates that for a firm with average $S A C A P$, simultaneous engagement of strategic and operational absorptive capacity increases the exploratory ability of the firm (Table 3.12 and Figure 3.9). The same effect is observed for incremental exploration, but with a lesser intensity (Table 3.13 and Figure 3.10).

This research also contributes to clarifying the apparent contradiction regarding the intensity of absorptive capacity exercised by the service and manufacturing sectors. My findings are in agreement with the conclusions reached by Arbussa and Coenders (2007) and Harris \& Le (2018) that service-sector firms have higher levels of exploration capabilities for increasing levels of absorptive capacity 
than manufacturing firms. Moreover, Figure 3.3 shows that for service companies, the larger the strategic absorptive capacity, the larger the effect on exploration.

Strategic absorptive capacity plays a significant role in both the exploratory ability and incremental exploitation of service companies, as shown in Figures 3.5 and 3.6. Quite a different behavior is shown for manufacturing companies; while for incremental exploitation $S A C A P$ has a similar influence for both industry sectors, it shows a diminishing return's behavior in its influence on exploration. Therefore, companies in the manufacturing sector with high levels of absorptive capacity might end up with disappointing exploratory findings (i.e., radical innovation or significant new knowledge) but strong incremental innovation results.

Similar behavior is observed between $S A C A P$ and exploration and incremental exploitation in the presence of collaboration. Firms already engaged in collaboration with other entities do not need to develop high levels of SACAP; actually, there are diminishing returns when it refers to the exploratory ability of the firm, as shown in Figure 3.5. On the contrary, collaboration slightly modifies the impact of $S A C A P$ on incremental exploitation, as shown in Figure 3.6. Interestingly, despite a firm's engagement in collaboration with other entities, it should develop significant SACAP to increase its ability to perform incremental exploitation.

Additionally, ambidexterity and absorptive capacity are affected over time by exogenous conditions like innovation tax incentives that significantly increase companies' spending in exploratory activities (Intelis, 2018).

Due to an unsuccessful attempt to implement innovation-incentive legislation in 2009, Chile introduced modifications to the law in 2012 to incentivize innovation 
within the firm, without any association requirement. This modification brought a significant increase in tax incentives applications, as shown in Figure 3.6. The release of the association requirement in the legislation brought an unwanted effect in the market, i.e., a substantial reduction of efforts to incorporate external new knowledge or technologies by the companies.

Therefore, the negative results observed validates the actual behavior of Chilean firms, i.e., the relationship between $S A C A P$ and EXPLORE weakens in the presence of the new incentive legislation. This behavior is corroborated in Figure 3.7, where the existence of new legislation disincentivized high levels of strategic absorptive capacities. The same phenomenon but to a lesser extent is observed for incremental exploitation; prior to the regulatory change, strategic absorptive capacity had a higher impact on incremental exploitation. After the legislative change, strategic absorptive capacity lost importance in terms of improving incremental exploitation. This is consistent with companies shifting to inward innovation efforts, rather than reaching outside for sources of innovation, either radical or incremental.

This research makes three contributions to the theory supporting ambidexterity and absorptive capacity. First, it provides a different view of the absorptive capacity construct. Prior research shows ACAP as a linear process (Cohen \& Levinthal, 1990; Todorova \& Durisin, 2007; Volberda, Foss, \& Lyles, 2010), while this study considers two levels: a strategic, related to value generation in the long run, and an operational, related to short-term goals. Also, reflecting on Patel et al. (2012), ambidexterity is considered as exploration, incremental exploitation, and repetitive exploitation, to better represent innovative and operational activities within the firm. Findings on the 
interaction of both constructs is a novel contribution to the theoretical understanding of the dynamics between external sources of knowledge and innovation and the ambidexterity capability of the firm. Second, this study contributes to the understanding of the moderating effects of two relevant variables, industry type (i.e., service vs. manufacturing), and collaboration practices. The longitudinal study also sheds light onto innovation-incentive legislation impact on the dynamics between the constructs. Third, the research shows a substantially different interacting behavior of exploration and incremental exploitation with ACAP; absorptive efforts show diminishing returns on exploration while showing an always positive trend for incremental exploitation.

From a practical perspective, managers tend to treat innovation knowledge separately from operational best practices. This study shows that the simultaneous application of both types of knowledge are complementary and contributes positively to the incremental innovation within the firm. This research contributes to the robustness of the guidance the ACAP/OA model could provide managers to develop criteria to reach outside their organizations for new knowledge and innovative sources. Insights are provided for service and manufacturing companies and on criteria for developing collaboration policies. Finally, it provides policy makers with some insights on the impacts of innovation-promotion legislation.

Despite the positive results, several limitations of the study should be addressed in future research. Single-source bias is present in the study since the data was collected from one secondary source. Since the original survey is based on the OECD innovation questionnaire, further research, including data from other countries using the same standard, would be promising to overcome this bias. The proxy 
utilized to represent the operational absorptive capacity variable, though significant and representative, comes from an innovation questionnaire and it is not fully operationally oriented. Future research should consider improving the operationalization of this variable.

Further, although the panel data allowed for a more detailed analysis of the relationship between absorptive capacity and ambidexterity, it was not powerful enough to allow for lagged effects. As more periods are incorporated in the future, lagged effects of the relevant variables should be considered and studied. 


\section{CHAPTER 4}

\section{CONCLUSIONS}

I began this study by introducing a gap in the literature regarding the direct relationship between absorptive capacity and organizational ambidexterity. The current business environment requires companies to reach out for new ideas, technologies, and best practices in order to maintain their competitive advantages. Several companies are living examples of sustained and adapted competitive advantages. 3M for example, with its teams of scouts, entrepreneurs and implementers transits from exploration to exploitation seamlessly and with significant value creation; another case is Ely Lilly, the pharmaceutical firm, with a research, development, and innovation collaboration program where the firm teams up with entrepreneurs and small firms in creating new molecules, products, and business cases. The IT sector has also evolved to include ambidexterity, with Cisco's entrepreneurs in residence program, the firm has reached out (absorptive capacity) to include entrepreneurs in the development of new products, processes or business models (ambidexterity). Finally, IBM's Watson open innovation business model, whereby the firm allows third parties to develop innovations using Watson is a good example of absorptive capacity and ambidexterity. IBM, finding the new application attractive, usually invests in the venture. This phenomenon is not only occurring at the firm level; entire industries are changing, like the electrical utility industry where new digital technology is transforming the operating area as well as the strategic level, including the business model, the utility-client and the utility-employee relationships. 
The necessary knowledge to deal with this significant change can not be found inside the utilities. They have to reach out for the proper knowledge, new practices, and technologies.

The original definition of ambidexterity proposed a dichotomy between exploration and exploitation, assimilating the former with $\mathrm{R} \& \mathrm{D}$ and radical innovation, and the latter with operational efficiency (March, 1991). There is a significant spectrum between both positions that was not fully captured by extant studies. Building upon an early study by Piao and Zajac (2016), I further categorize exploitation as incremental exploitation, which is associated with incremental innovation, and repetitive exploitation, which is associated with operational efficiency.

Absorptive capacity has become increasingly relevant since the construct was introduced by Cohen \& Levinthal (1990), but has been focused mostly on innovation and strategic change. However, organizations have always reached out for new knowledge or best practices, regardless of whether they were related to operations or new competitive advantages. Instead of treating absorptive capacity as a phenomenon exclusively in the realm of innovation or operations as the extant literature suggests, this study combines the observation of both research streams into a construct with two elements, strategic absorptive capacity that is related to innovation, and operational absorptive capacity related to innovation as well as operational efficiency.

Focusing on organizational units, the objective of this study is to understand how absorptive capacity at the strategic and operational levels affects organizational ambidexterity. Piao and Zajac (2016) have explored this relationship, but only at the strategic level of absorptive capacity. Moreover, they focus only on one case study, 
which limits the generalizability of the findings. In Chapter 2, I used cross-sectional data and found a positive relationship between strategic absorptive capacity and exploration. More relevantly, Chapter 2 shows the positive effect of both strategic absorptive capacity and operational absorptive capacity on incremental exploitation. These findings indicate that the effort of improving existing products, services and processes is better served with contributions from innovative and operational external knowledge. Also, as expected from the extant operational literature, operational absorptive capacity has a positive impact on repetitive exploitation.

The proposed model of absorptive capacity in Chapter 2, which includes an innovative and operational dimension simultaneously, is novel and contributes to the knowledge of this construct. Moreover, since absorptive capacity as an antecedent of ambidexterity has not been studied extensively before, this study contributes to theory by validating the hypothesis of the influence of innovative and operational absorptive capacity on incremental exploitation.

Chapter 3 focuses on how the relationship between both constructs varies over a six-year period and is moderated by firm-, sector-, and policy-level factors. From a sector point of view, the results indicate that the impact of strategic absorptive capacity for exploration is stronger for service firms than for manufacturing firms. Figure 3.2 shows that for service companies the larger the strategic absorptive capacity, the larger the effect on exploration. Figure 3.2 also shows that for services and manufacturing firms with an average level of strategic absorptive capacity, absorptive capacity has a higher impact on exploration. One could conclude from this pattern that service firms have to try to maximize their absorptive capabilities in order to obtain a significant level of exploration. 
For non-collaborating and collaborating firms with other companies or institutions with the same level of strategic absorptive capacity and no interaction term, collaborating companies have a larger positive impact on exploration $(10.9 \%$ at the 0.05 level). The moderating effect amplifies the impact more than double, to $22 \%$, i.e., those that collaborate have $22 \%$ more influence on exploration than noncollaborative firms. Figure 3.4 shows that the incremental effort on strategic absorptive capacity has diminishing returns, so a company with absorptive capacity and collaboration should moderate the use of such capacity because the effect on exploration diminishes.

Original innovation-incentive legislation was passed in Chile in 2009. The mechanism required collaboration with an external research institution, either a university or other institution duly accredited by the Innovation Agency. The effect of the legislation was not significant since, according to some reports, the process was cumbersome, and relationships between industry and academia were almost nonexistent. Due to the lack of success, the legislation was modified in 2012 to incentivize innovation within the firm, without the previous requirement. This modification brought a significant increase in the application for tax incentives, as shown in Figure 3.6. However, this increase disincentivized those firms that reach outside to look for innovation sources. The results I have found validates the actual behavior of Chilean firms. That is, the relationship between strategic absorptive capacity and exploration is weaker due to the new incentive legislation since Chilean firms did not use absorptive capacity for their exploratory efforts. This pattern is 
corroborated in Figure 3.7, where the existence of new legislation disincentivized high levels of strategic absorptive capacity.

The study also explores the effect of strategic absorptive capacity on incremental exploitation, defined as incremental modifications of existing products or services. The impact of strategic absorptive capacity on incremental exploitation is substantially different for those moderators previously analyzed. Companies from the manufacturing and service sectors with average strategic absorptive capacity have roughly the same impact on incremental exploitation. However, for larger efforts on absorptive capacity, service companies do have a better impact on incremental exploitation than manufacturing firms. From the exploratory and incremental exploitation analysis, one could conclude that service companies should seek higher levels of absorptive capacity than manufacturing firms.

A similar pattern is observed for collaborative and non-collaborative firms. At the average level of strategic absorptive capacity for both types of companies, the exploration impact is higher for the latter, but for higher levels of strategic absorptive capacity, collaborative firms show a higher impact on exploration than noncollaborative firms.

In the case of the impact of new innovation legislation, recalling that the modification of the legislation incentivized in-house innovation, prior to the regulatory change strategic absorptive capacity had a higher impact on incremental exploitation. After the legislative change, strategic absorptive capacity lost importance in terms of improving incremental exploitation. This is consistent with companies 
shifting to inward innovation efforts, rather than reaching outside for sources of innovation, either radical or incremental.

Managers tend to treat innovation knowledge separately from operational or efficiency best practices. This study shows that the simultaneous application of both types of knowledge contributes positively to the incremental innovation within the firm. This research contributes to the robustness of the guidance the absorptive capacity-organizational ambidexterity model could provide for managers to develop criteria to reach outside their organizations for new sources of knowledge and innovative. It also provides managers with important insights into the length of time it will take for their organizations to develop absorptive capacity and how this affects ambidexterity over time. 


\section{REFERENCES}

Adler, P. S., Goldoftas, B., \& Levine, D. I. (1999). Flexibility versus efficiency? A case study of model changeovers in the Toyota production system. Organization Science, 10(1), 43-68. doi:10.1287/orsc.10.1.43

Ahuja, G., \& Morris Lampert, C. (2001). Entrepreneurship in the large corporation: A longitudinal study of how established firms create breakthrough inventions. Strategic Management Journal 22(6/7), 521.543, doi:10.1002/smj.176

Álvarez, R., Bravo-Ortega, C., \& Zahler, A. (2015). Innovation and productivity in services: Evidence from Chile. Emerging Markets Finance and Trade, 51(3), 593-611. doi:10.1080/1540496X.2015.1026696

Anand, J., Mulotte, L., \& Ren, C. R. (2016). Does experience imply learning? Strategic Management Journal, 37(7), 1395-412.

Arbussa, A., \& Coenders, G. (2007). Innovation activities, use of appropriation instruments and absorptive capacity: Evidence from Spanish firms. Research Policy, 36(10), 1545-1558.

Benner, M. J., \& Tushman, M. L. (2003). Exploitation, exploration, and process management: The productivity dilemma revisited. The Academy of Management Review, 28(2), 238-256. doi:10.5465/AMR.2003.9416096

Birkinshaw, J., \& Gupta, K. (2013). Clarifying the distinctive contribution of ambidexterity to the field of organization studies. The Academy of Management Perspectives, 27(4), 287. doi:10.5465/amp.2012.0167 
Boumgarden, P., Nickerson, J., \& Zenger, T. R. (2012). Sailing into the wind:

Exploring the relationships among ambidexterity, vacillation, and organizational performance. Strategic Management Journal, 33(6), 587-610.

doi:10.1002/smj.1972

Cano-Kollmann, M., Hamilton III, R. D., \& Mudambi, R. (2016). Public support for innovation and the openness of firms' innovation activities. Industrial and Corporate Change, 26(3), 421-442.

Cassiman, B., \& Veugelers, R. (1998). R\&D cooperation and spillovers: Some empirical evidence. Universitat Pompeu Fabra Economics WP, (328)

Chesbrough, H. W. (2006). Open innovation: The new imperative for creating and profiting from technology. Boston: Harvard Business School Press.

Cohen, W. M., \& Levinthal, D. A. (1989). Innovation and learning: The two faces of R\&D. Economic Journal, 99(397), 569-96.

Cohen, W. M., \& Levinthal, D.(1990). Absorptive capacity: A new perspective on learning and innovation. Administrative Science Quarterly, 35(1), 128-152.

Datta, A. (2012). IT-based knowledge capability and commercialization of innovations: Modeling the impacts of ambidexterity and absorptive capacity. International Journal of Knowledge Management (IJKM), 8(3), 83-97. doi:10.4018/jkm.2012070105

de Jong, J., \& Freel, M. (2010). Absorptive capacity and the reach of collaboration in high technology small firms. Research Policy, 39(1), 47. doi:10.1016/j.respol.2009.10.003 
Duncan, R. B. (1976). The ambidextrous organization: Designing dual structures for innovation. In R. H. Kilmann, L. R. Pondy \& D. Slevin (Eds.), The management of organization design: Strategies and implementation (pp. 167-88). New York: North Holland.

Dutta, S., Lanvin, B., \& Wunsch-Vincent, S. (2016). The global innovation index 2016: Winning with global innovation. Ithaca, Fontainebleau, and Geneva; Cornell University, INSEAD, and WIPO.

Fayard, D., Lee, L. S., Leitch, R. A., \& Kettinger, W. J. (2012). Effect of internal cost management, information systems integration, and absorptive capacity on interorganizational cost management in supply chains. Accounting, Organizations, and Society, 37, 168-87. https://doiorg.libproxy.temple.edu/10.1016/j.aos.2012.02.001

Feinberg, S. E., \& Gupta, A. K. (2004). Knowledge spillovers and the assignment of R\&D responsibilities to foreign subsidiaries. Strategic Management Journal, 25(8/9), 823-845. doi:10.1002/smj.396

Fitzmaurice, G. M., Laird, N. M., \& Ware, J. H. (2012). Applied longitudinal analysis Hoboken, NJ: John Wiley \& Sons.

Fukugawa, N. (2006). Determining factors in innovation of small firm networks: A case of cross industry groups in japan. Small Business Economics, 27(2/3), 18193. doi:10.1007/s11187-006-0010-2

Geerts, A., Blindenbach-Driessen, F., \& Gemmel, P. (2010). Achieving a balance between exploration and exploitation in service firms: A longitudinal study. Paper presented at the Academy of Management Proceedings, , 2010(1) 1-6. 
Ghemawat, P. (2002). Competition and Business Strategy in Historical Perspective. The Business History Review, 76(1), 37-74. Retrieved from http://www.jstor.org/stable/4127751

Goodburn, M. (2015). What is the life expectancy of your company? Retrieved from https://www.weforum.org/agenda/2015/01/what-is-the-life-expectancy-of-yourcompany/

Grant, R. (1996). Toward a knowledge-based theory of the firm. Strategic Management Journal., 17(S2), 109-122.

Guellec, D., \& van Pottelsberghe de la Potterie, B. (2002). R\&D and productivity growth. OECD Economic Studies, 2001(2), 103-126.

Gupta, A. K., Smith, K. G., \& Shalley, C. E. (2006). The interplay between exploration and exploitation. The Academy of Management Journal, 49(4), 693706. doi:10.5465/AMJ.2006.22083026

Harris, R., \& Le, T. (2018). Absorptive capacity in New Zealand firms: Measurement and importance. (Motu Working Papers 18-01). Wellington, New Zealand: Motu Economic and Public Policy Research.

Harris, R., \& Moffat, J. (2011). R\&D, innovation and exporting. (SERC Discussion Paper 73). Glasgow: SERC, CPPR, and the University of Glasgow.

Harris, R., \& Moffat, J. (2013). Intangible assets, absorbing knowledge and its impact on firm performance: Theory, measurement and policy implications. Contemporary Social Science, 8(3), 346-361.

Helfat, C. E., \& Peteraf, M. A. (2003). The dynamic resource-based view: Capability lifecycles. Strategic Management Journal, 24, 997-1010. doi:10.1002/smj.332 
Helfat, C. E., \& Winter, S. G. (2011). Untangling dynamic and operational capabilities: Strategy for the (N)ever-Changing world. Strategic Management Journal, 32(11), 1243-1250. doi:10.1002/smj.955

Hoffmann, W., Lavie, D., Reuer, J. J., \& Shipilov, A. (2018). The interplay of competition and cooperation. Strategic Management Journal, 39(12), 3033-3052.

Intelis. (2018). Estudio de evaluación de la ley de incentivo tributario a la inversión en $i+d$. Retrieved from http://www.economia.gob.cl/2017/04/27/informe-finalevaluacion-ley-id.htm

Junni, P., Sarala, R., Taras, V., \& Tarba, S. (2013). Organizational ambidexterity and performance: A meta-analysis. The Academy of Management Perspectives, 27(4), 299. doi:10.5465/amp.2012.0015

Kedia, B. L., \& Bhagat, R. S. (1988). Cultural constraints on transfer of technology across nations: Implications for research in international and comparative management. The Academy of Management Review, 13(4), 559-71. doi:10.5465/AMR.1988.4307424

Kim, L. (1998). Crisis construction and organizational learning: Capability building in catching-up at Hyundai motor. Organization Science, 9(4), 506-21. doi:10.1287/orsc.9.4.506

Lane, P. J., Salk, J. E., \& Lyles, M. A. (2001). Absorptive capacity, learning, and performance in international joint ventures. Strategic Management Journal, 22(12), 1139-1161. doi:10.1002/smj.206 
Lavie, D. (2006). The competitive advantage of interconnected firms: An extension of the resource-based view. Academy of Management Review, 31(3), 638-58. doi:10.5465/amr.2006.21318922

Lavie, D., \& Rosenkopf, L. (2006). Balancing exploration and exploitation in alliance formation. Academy of Management Journal, 49(4), 638-58 doi:10.5465/amj.2006.22083085

Levinthal, D. A., \& March, J. G. (1993). The myopia of learning. Strategic Management Journal, 14(S2), 95-112. doi:10.1002/smj.4250141009

Lichtenthaler, U. (2009). Absorptive capacity, environmental turbulence, and the complementarity of organizational learning processes. Academy of Management Journal, 52(4), 822-46. doi:10.5465/AMJ.2009.43670902

Lin, H., Zeng, S., Liu, H., \& Li, C. (2016). How do intermediaries drive corporate innovation? A moderated mediating examination. Journal of Business Research, 69(11), 4831-36. doi:https://doi.org/10.1016/j.jbusres.2016.04.039

Lucena, A., \& Roper, S. (2016). Absorptive capacity and ambidexterity in R\&D: Linking technology alliance diversity and firm innovation. European Management Review, 13(3), 159-78. doi:10.1111/emre.12074

Malhotra, A., Gosain, S., \& Sawy, O. A. E. (2005). Absorptive capacity configurations in supply chains: Gearing for partner-enabled market knowledge creation. MIS Quarterly, 29(1), 145-87.

March, J. G. (1991). Exploration and exploitation in organizational learning. Organization Science, 2(1), 71-87. Retrieved from http://www.jstor.org/stable/2634940 
3M. (2003). A century of innovation: The 3M story. St.Paul, MN: 3M Company.

Milliken, F. J., \& Martins, L. L. (1996). Searching for common threads:

Understanding the multiple effects of diversity in organizational groups. The Academy of Management Review, 21(2), 402-433. doi:10.2307/258667

Mina, A., Bascavusoglu-Moreau, E., \& Hughes, A. (2014). Open service innovation and the firm's search for external knowledge. Research Policy, 43(5), 853-866. doi:https://doi.org/10.1016/j.respol.2013.07.004

Mudambi, R., \& Swift, T. (2011). Proactive R\&D management and firm growth: A punctuated equilibrium model. Research Policy, 40(3), 429-440. doi:10.1016/j.respol.2010.10.014

Mudambi, R., \& Swift, T. (2014). Knowing when to leap: Transitioning between exploitative and explorative R\&D. Strategic Management Journal, 35(1), 126145. doi:10.1002/smj.2097

Narasimhan, R., \& Narayanan, S. (2013). Perspectives on supply network-enabled innovations. Journal of Supply Chain Management, 49(4), 27-42.

Netter, J., Wasserman, W., \& Kutner, M. (1990). Applied linear statistical models. New York, Irwin.

O’Reilly, C. A., \& Tushman, M. L. (2008). Ambidexterity as a dynamic capability: Resolving the innovator's dilemma. Research in Organizational Behavior, 28, 185-206. doi:10.1016/j.riob.2008.06.002

OECD. (2018). In OECD (Ed.), OECD economic surveys: Chile 2018 OECD Publishing. doi:10.1787/eco_surveys-chl-2015-en 
O'Reilly, C., \& Tushman, M. (2013). Organizational ambidexterity: Past, present and future. The Academy of Management Perspectives, 27(4), 324. doi:10.5465/amp.2013.0025

Organisation for Economic Co-operation and Development. (1997). The measurement of scientific and technological activities: Proposed guidelines for collecting and interpreting technological innovation data: Oslo manual OECD. Oslo: European Commission, Eurostat.

Papadakis, V. M., Lioukas, S., \& Chambers, D. (1998). Strategic decision-making processes: The role of management and context. Strategic Management Journal, 19(2), 115-147.

Park, H. M. (2011). Practical guides to panel data modeling: A step by step analysis using stata. Public Management and Policy Analysis Program, Graduate School of International Relations, International University of Japan, 1-52.

Patel, P. C., Terjesen, S., \& Li, D. (2012). Enhancing effects of manufacturing flexibility through operational absorptive capacity and operational ambidexterity. Journal of Operations Management, 30(3), 201-220.

doi:10.1016/j.jom.2011.10.004

Phelps, C. C. (2010). A longitudinal study of the influence of alliance network structure and composition on firm exploratory innovation. The Academy of Management Journal., 53(4), 890-913. doi:10.5465/amj.2010.52814627

Piao, M., \& Zajac, E. J. (2016). How exploitation impedes and impels exploration: Theory and evidence. Strategic Management Journal, 37(7), 1431-1447. doi:10.1002/smj.2402 
Podsakoff, P. M., \& Organ, D. W. (1986). Self-reports in organizational research: Problems and prospects. Journal of Management, 12(4), 531-544.

Quintana-García, C., \& Benavides-Velasco, C. (2008). Innovative competence, exploration and exploitation: The influence of technological diversification. Research Policy, 37(3), 492-507. doi:10.1016/j.respol.2007.12.002

Raisch, S., \& Birkinshaw, J. (2008). Organizational ambidexterity: Antecedents, outcomes, and moderators. Journal of Management, 34(3), 375-409. doi:10.1177/0149206308316058

Ren, C. R., \& Guo, C. (2011). Middle managers' strategic role in the corporate entrepreneurial process: Attention-based effects. Journal of Management, 37(6), 1586-1610.

Ritala, P., \& Hurmelinna-Laukkanen, P. (2013). Incremental and radical innovation in coopetition - The role of absorptive capacity and appropriability. Journal of Product Innovation Management, 30(1), 154-69.

Rothaermel, F. T., \& Deeds, D. L. (2004). Exploration and exploitation alliances in biotechnology: A system of new product development. Strategic Management Journal, 25(3), 201-21. doi:10.1002/smj.376

Santamaría, L., Nieto, M. J., \& Barge-Gil, A. (2009). Beyond formal R\&D: Taking advantage of other sources of innovation in low-and medium-technology industries. Research Policy, 38(3), 507-517.

Savin, I., \& Egbetokun, A. (2016). Emergence of innovation networks from R\&D cooperation with endogenous absorptive capacity. Journal of Economic Dynamics and Control, 64, 82-103. oi:https://doi.org/10.1016/j.jedc.2015.12.005 
Schwab, K., \& Sala-i-Martin, X. (2018). The global competitiveness report 20162017. Geneva: World Economic Forum.

Setia, P., \& Patel, P. C. (2013). How information systems help create OM capabilities: Consequents and antecedents of operational absorptive capacity. Journal of Operations Management, 31(6), 409-431. doi:https://doi org.libproxy.temple.edu/10.1016/j.jom.2013.07.013

Smith, W. K., \& Tushman, M. L. (2005). Managing strategic contradictions: A top management model for managing innovation streams. Organization Science, 16(5), 522-36. doi:10.1287/orsc.1050.0134

Sørensen, J. B., \& Stuart, T. E. (2000). Aging, obsolescence, and organizational innovation. Administrative Science Quarterly, 45(1), 81-112. doi: $10.2307 / 2666980$

Spithoven, A., Clarysse, B., \& Knockaert, M. (2011). Building absorptive capacity to organise inbound open innovation in traditional industries. Technovation, 30(2), 130-41. doi:https://doi.org/10.1016/j.technovation.2010.10.003

Spithoven, A., Clarysse, B., \& Knockaert, M. (2011). Building absorptive capacity to organise inbound open innovation in traditional industries.

Swift, T. (2016). The perilous leap between exploration and exploitation. Strategic Management Journal, 37(8), 1688-98. doi:10.1002/smj.2423

Teece, D. J. (2007). Explicating dynamic capabilities: The nature and microfoundations of (sustainable) enterprise performance. Strategic Management Journal, 28(13), 1319-1350. 
Todorova, G., \& Durisin, B. (2007). Absorptive capacity: Valuing a reconceptualization. The Academy of Management Review, 32(3), 774-786. doi:10.5465/AMR.2007.25275513

Tu, Q., Vonderembse, M. A., Ragu-Nathan, T. S., \& Sharkey, T. W. (2006). Absorptive capacity: Enhancing the assimilation of time-based manufacturing practices. Journal of Operations Management, 24(5), 692-710. doi:10.1016/j.jom.2005.05.004

Tushman, M. L., \& O'Reilly, C. A. (1996). The ambidextrous organizations: Managing evolutionary and revolutionary change. California Management Review, 38(4), 8-30. doi:10.2307/41165852

United Nations, S. D. (2004). In United Nations. Statistical Division (Ed.), International standard industrial classification of all economic activities (ISIC) (Revision 3.1 ed.). New York: New York : United Nations.

Uotila, J., Maula, M., Keil, T., \& Zahra, S. A. (2009). Exploration, exploitation, and financial performance: Analysis of S\&P 500 corporations. Strategic Management Journal, 30(2), 221-231. doi:10.1002/smj.738

van Wijk, R., Jansen, J. J. P., Van Den Bosch, F. A. J., \& Volberda, H. W. (2012). How firms shape knowledge to explore and exploit: A study of knowledge flows, knowledge stocks and innovative performance across units. Technology Analysis \& Strategic Management, 24(9), 929-950. doi:10.1080/09537325.2012.718666

Venkatraman, N., Lee, C., \& Iyer, B. (2007). Strategic ambidexterity and sales growth: A longitudinal test in the software sector. Unpublished Manuscript, Boston University School of Management, Boston. 
Volberda, H. W., Foss, N. J., \& Lyles, M. A. (2010). Absorbing the concept of absorptive capacity: How to realize its potential in the organization field. Organization Science, 21(4), 931-951. doi:10.1287/orsc.1090.0503

Wales, W. J., Parida, V., Patel, P. C. (2013). Too much of a good thing? absorptive capacity, firm performance, and the moderating role of entrepreneurial orientation. Strategic Management Journal, 34(5), 622-33. doi:10.1002/smj.2026

Wang, C. L., \& Ahmed, P. K. (2007). Dynamic capabilities: A review and research agenda. International Journal of Management Reviews, 9(1), 31-51. doi:10.1111/j.1468-2370.2007.00201.x

Yan, M., Yu, Y., \& Dong, X. (2016). Contributive roles of multilevel organizational learning for the evolution of organizational ambidexterity. Information Technology \& People, 29(3), 647-67. doi:10.1108/ITP-04-2015-0079

Zahra, S. A., \& Nielsen, A. P. (2002). Sources of capabilities, integration and technology commercialization. Strategic Management Journal, 23(5), 377-398.

Zahra, S. A., \& George, G. (2002). Absorptive capacity: A review, reconceptualization, and extension. The Academy of Management Review, 27(2), 185-203. doi:10.5465/AMR.2002.6587995

Zhou, K. Z., \& LI, C. B. (2012). How knowledge affects radical innovation: Knowledge base, market knowledge acquisition, and internal knowledge sharing. Strategic Management Journal, 33(9), 1090-1102. doi:10.1002/smj.1959 